\title{
LAS CIENCIAS DE LA TIERRA Y LA BIBLIA. UNA APROXIMACIÓN DESDE LA RAZÓN CIENTÍFICA
}

\author{
Francisco J. Ayala-Carcedo \\ Comisión Internacional de Historia de la Geología, INHIGEO (UNESCO) \\ Instituto Geológico y Minero de España-Ministerio de Educación y Ciencia
}

\section{RESUMEN}

El desarrollo de la Ciencia, Natural e Histórica, ha ido aportando nuevos elementos que permiten una aproximación a los relatos bíblicos desde la perspectiva de la razón científica. En este sentido, se presenta una aproximación científica, básicamente desde las Ciencias de la Tierra y teniendo en cuenta la realidad histórica del pueblo hebreo y la propia Biblia, al relato de la Creación, y los posibles núcleos histórico-científicos de los relatos del Diluvio Universal y la destrucción de Sodoma y Gomorra, de acuerdo con los últimos conocimientos disponibles. Por otra parte, se analizan los condicionamientos que los relatos bíblicos, especialmente la Creación y el Diluvio, impusieron históricamente al surgimiento de las Ciencias Geológicas.

Palabras clave: Biblia, Ciencias de la Tierra, Creación, Creacionismo Científico, Diluvio, Geografía Física, Geología, Geología Bíblica, Historia de la Geología, Paleontología, Sodoma y Gomorra.

\section{ABSTRACT}

Earth Sciences and Bible. An Approach from Scientific Reason

The Science, Natural and Historic, development, has supplied new insights for a scientific approach to biblical stories. In this way, taking into account the historical reality of the Hebrew people and the Bible, a scientific approach mainly from the Earth Sciences to story of Creation, and the possible historical cores of biblical stories as the Noah's Flood and the Sodom and Gomorrah destruction, according with the last available information, is presented. Also, the constraints posed historically by the biblical texts to the Geological Sciences development, specially the Creation and the Noah's Flood, are analysed.

Key words: Bible, Biblical Geology, Creation, Earth Sciences, Geology, History of Geology, Noah’s Flood, Paleontology, Physical Geography, Scientific Creationism, Sodom and Gomorrah. 
«La verdad os hará libres»

Jesús de Galilea, según el Evangelio de San Juan, 8, 32

«Estamos entregados a nosotros mismos; nadie nos protege ni nos dirige. Si no tenemos confianza en nosotros, todo se habrá perdido»

Verdad y perspectiva. El Espectador, T. I, 1916

José Ortega y Gasset

\section{Introducción y metodología}

Este artículo presenta, de forma introductoria, una aproximación crítica a la relación Biblia-Ciencias de la Tierra, con un énfasis especial en la Cosmología, Geografía Física y Geología en torno a algunos temas concretos. Se trata de ver lo que resulta cuestionado o reinterpretado del relato bíblico tras varios siglos de descubrimientos desde la Revolución Científica del XVII. Un asunto de gran interés cultural, relevante tanto para la Historia como para la Sociología y Antropología de la Ciencia, y por supuesto para una comprensión cabal de la Biblia en nuestros tiempos. La relación existente, se muestra, de acuerdo con el estado actual de conocimientos, en dos aspectos principales y en ambos sentidos de influencia.

El primer aspecto presenta, de acuerdo con las últimas investigaciones, las contribuciones de la Geografía Física y la Geología, conjuntamente con otras ciencias como la Historia, Cosmología o Biología, a la comprensión y crítica científicas de algunos relatos bíblicos como la Creación, el Diluvio Universal y la destrucción de Sodoma y Gomorra. El segundo aspecto, ligado al primero dada la fuerte influencia de los textos bíblicos sobre las condiciones históricas del progreso científico en sus primeras fases, analiza el papel de la Biblia en el desarrollo histórico de las Ciencias Geológicas.

Esta aproximación lleva a algo muy distinto de la llamada Geología Bíblica, disciplina pseudocientífica que pretende nada menos que haber elaborado una «geología» a partir de los relatos bíblicos, alternativa y superior a la construida por los geólogos los últimos siglos, para la cual se reivindica, ironía de los tiempos, marcados por el éxito explicativo de la Ciencia, un carácter científico y contrastable (Froede \& Reed, 1999).

Por tanto, la temática de esta aproximación científica, poco cultivada en los países católicos por lo limitado de la cultura bíblica entre el gran público, y entre los propios científicos naturales por lo obvio para ellos de los errores bíblicos, abarca tanto la aproximación geomitológica que sintetizó y popularizó Dorothy Vitaliano en 1973, aplicada en este caso solo a la Biblia y los relatos míticos que influyeron en ella, como aquellos aspectos de la Historia de la Geología interrelacionados y condicionados por la temática bíblica, singularmente el Diluvismo y la polémica sobre el origen de los fósiles que han analizado diversos autores españoles (Capel, 1985; Pelayo, 1996).

El interés de esta temática, habitualmente orillada por la comunidad científica, se acrecienta actualmente por dos motivos. El primero es la necesidad de hacer frente, científicamente y en todo aquello que toca con la Ciencia, al resurgir del fundamentalismo cristiano, importante en EE.UU., Latinoamérica y Australia, pero ya visible en países como el Reino Unido, Italia y España. El segundo, específico del caso español, tiene que ver con la reciente reintroducción, 25 años después del fin jurídico-constitucional del nacionalcatolicismo franquista, de la enseñanza religiosa obligatoria a nivel oficial en 2003 por el gobierno español del Partido Popular, presidido por José María Aznar y con significativa 
presencia de militantes y simpatizantes de organizaciones católicas conservadoras. Esta decisión, que obliga a seguir a los alumnos no creyentes una asignatura denominada «Sociedad, Cultura y Religión», ha sido ampliamente contestada a nivel social y político por el carácter laico del Estado Español desde la Constitución de 1978. En este contexto, los astrofísicos, geógrafos, geólogos, y, en general los científicos, enseñantes o no, pueden y deberían contribuir a una formación y debate más rico y profundo aportando sus conocimientos para el entendimiento del hecho religioso y las bases del Cristianismo.

La fuente de la importancia clave que la Biblia ha tenido y tiene, proviene de su atribución divina, fruto de un acto de fe, tanto para los judíos como para los cristianos. Según Juan Pablo II (1980): «Dios la inspiró, Dios la confirmó, Dios la pronunció por medio de los hagiógrafos ${ }^{1} »$.

Hoy en día, la práctica del Cristianismo, surgido en una civilización agraria hace dos milenios, ha decaído significativamente en los países más desarrollados como previera Guyau (1887), tal y como prueban las cifras oficiales en España para 2002: tan sólo un 33,3\% de los contribuyentes deciden financiar a la Iglesia católica con sus impuestos y solo un $18 \%$ cumplen con el rito obligado de la misa dominical, porcentaje que baja drásticamente entre los jóvenes urbanos: 3,5\% en Barcelona entre los menores de 25 años. Esta no era, sin embargo, la realidad histórica de las épocas del surgimiento de la Ciencia moderna, con una influencia sociopolítica y económica de la Iglesia mucho mayor en un mundo agrario (Gillispie, 1959), influencia a la que no escaparon los osados científicos de la época cuyos hallazgos cuestionaban la ortodoxia bíblica como prueba el caso Galileo.

El análisis de la relación entre las Sagradas Escrituras de judíos y cristianos y la Ciencia, necesita de una aproximación histórica, no anacrónica, teniendo en cuenta que la Ciencia tal y como hoy la conocemos es un fenómeno que no tiene más allá de cuatro siglos, y unos dos siglos en Geología o Biología. Quiere ello decir que debemos juzgar la veracidad de los relatos bíblicos, su contenido de verdad - ante todo histórica, su historicidad - desde nuestros conocimientos científicos actuales, ya que la verdad es la que es, pero cometeríamos un gran error si juzgáramos su influencia sobre el surgimiento histórico de la Geología como ciencia, desde el presente y sin relación con la realidad histórica concreta del pasado, ya que la verosimilitud de los relatos bíblicos, su credibilidad en un contexto cultural histórico, en ausencia de desarrollo científico, era mucho mayor en el pasado. Por tanto, es necesario mostrar en paralelo los dos campos para evitar el anacronismo metodológico: el histórico-científico y el derivado de las Ciencias de la Naturaleza. Más adelante, en torno al análisis de algunos de los textos, se hacen más precisiones metodológicas.

Este artículo, por tanto, tiene como objetivo central el análisis de la veracidad y verosimilitud de aquellas proposiciones y textos que son susceptibles de verificación científica. Los aspectos doctrinales, sólo se analizan críticamente en algunos aspectos metodológicos relevantes para el análisis anterior o que resultan afectados por la crítica científica. Los aspectos ligados a la práctica religiosa, cuando son realizados sinceramente, sin fines proselitistas ni imposiciones, en especial la solidaridad con el prójimo de algunos creyentes y religiosos, rayana a veces en la abnegación, cuentan con el profundo respeto y simpatía del autor de estas líneas. Filosóficamente, la motivación del trabajo concuerda en la textualidad con las palabras del epígrafe que San Juan atribuye a Jesús de Galilea sobre la verdad (asimilada por el evangelista a la Revelación), como condición necesaria de la libertad. En este sentido, debería ser visto como una contribución desde el humanismo

1 Hagiógrafo: autor bíblico. 
laico, necesariamente crítica, a veces algo irónica ante alguna de las burdas falsificaciones o errores, pero siempre rigurosa. Una aportación hecha con intención de provocar la reflexión, al proceso de aggiornamento, de revisión y autocrítica, que la aparición de la Ciencia, el progreso de la Tecnología y los profundos y extensos cambios sociales generados, han impuesto desde la Ilustración al fenómeno religioso. Un proceso comenzado tardíamente en el caso de la religión católica por el Concilio Vaticano II (1962-65) que tan certeramente impulsó el papa de la apertura y el diálogo, Juan XXIII.

Previamente a los comienzos de la Ciencia moderna, y hasta hace poco más de un siglo para gran parte de la Humanidad, la necesidad humana de encontrar explicación a los fenómenos naturales y a las propias incertidumbres que rodean $-\mathrm{y}$ probablemente rodeen siempre - la vida humana y su final, llevaba frecuentemente a explicaciones basadas en la antropomorfización de las fuerzas y procesos naturales, entonces «explicaciones» verosímiles (Eliade, 1951; Lévi-Strauss, 1966). Esta aproximación, era comprensible entonces por lo limitado del conocimiento disponible, y es la base común tanto de la mayoría de los mitos y religiones, como del espiritismo y la creencia en la vida tras la muerte a través de la supervivencia del alma — un concepto carente de estatus científico (Bunge, 1985) de clara raíz animista-, creencias surgidas en épocas precientíficas.

\section{La historia del antiguo pueblo hebreo y la historia de la Biblia: una historia común}

No resulta posible comprender el papel de la Biblia en la Historia de la Geología, ni tampoco evaluar científicamente la veracidad de algunos de sus relatos, sin algún conocimiento de su historia y su relación necesaria con la historia antigua del pueblo hebreo (Vid. p.e. Coogan, 1998). Este conocimiento es asimismo fundamental para cualquier intento de comprensión racional de los propios aspectos doctrinales, en realidad incomprensibles sin esta condición. Como se dijo, este conocimiento es bastante menor en los medios católicos que en los protestantes, ya que para estos últimos, la lectura directa de la Biblia, fuente central de autoridad, es clave en su práctica religiosa, mientras los católicos suelen obtener su información indirectamente, a través de las «historias sagradas» eclesiásticas que se enseñan en las escuelas, lo que les dificulta objetivamente una aproximación directa y crítica a los textos. Unos textos, por otra parte, cuya traducción a las lenguas vulgares estuvo prohibida por la Iglesia católica durante siglos, hasta el punto de que todavía en el siglo XIX la lectura de la Biblia en castellano en España era sinónimo de protestantismo y el inglés George Burrow, vendedor de biblias baratas por los pueblos a lomos de mula, acabaría en la cárcel (Sánchez Caro, 1998).

La Biblia — del griego biblos, libro - se compone de dos colecciones de libros agrupadas en sendos Testamentos. El más antiguo, el Antiguo Testamento (AT) de los cristianos, fue según hebreos y cristianos, inspirado por Yahvé, el dios nacional hebreo (YHWH en el idioma consonántico hebreo), Dios único para ambas confesiones, y relata supuestamente tanto la historia de la Tierra como la del pueblo hebreo en el contexto de los antiguos pueblos mesopotámicos y de Oriente Medio.

La parte más reciente, el Nuevo Testamento (NT), escrito a partir del periodo 67-70, solo existe en la Biblia cristiana, ya que los hebreos - testigos directos de su vida, que, sorprendentemente, no deja huella histórica entre los judíos- no otorgan a Jesús de Galilea, el Cristo («el ungido» en griego), el Mesías («el enviado» en hebreo) salvador cristiano, ni naturaleza divina —algo impensable en la Teología hebraica y que generó fuertes polémicas para su aceptación entre los primeros cristianos-, ni importancia alguna en su tradición. Un agudo contraste con lo que se desprende de los Evangelios puede verse p.e. en las Antigüedades Judías del historiador judío Flavio Josefo, contemporáneo de la 


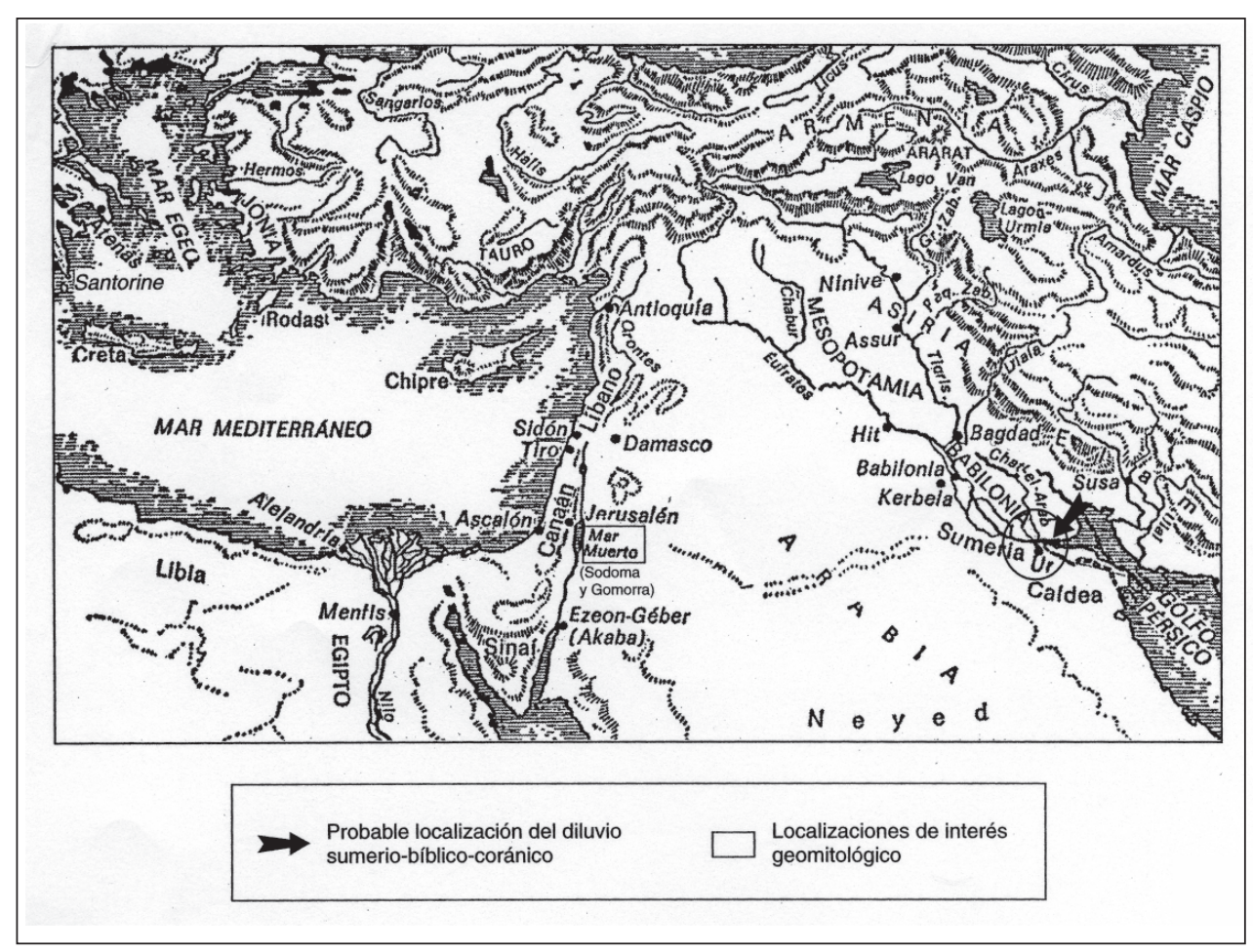

Figura 1. Marco físico-geográfico del pueblo hebreo antiguo y la Biblia. Inicialmente un pequeño pueblo pastor y agricultor de las tierras altas cananeas entre dos grandes imperios del Segundo Milenio, Asiria y Egipto, acabaría instalándose en toda Palestina, el Canaán bíblico, la «Tierra Prometida» por Yahvé. Véase la probable localización del supuesto Diluvio Universal, en el antiguo Sumer, y de Sodoma y Gomorra (Henning, 1950, mod. por Ayala-Carcedo, 2002).

Diáspora del 70, solo con una referencia a Jesús con alguna posibilidad de ser verdadera, indirecta y minúscula, como hermano de Santiago. Los textos evangélicos, junto a obras como el Contra los judios de Tertuliano, han contribuido, por otra parte, a cimentar el antisemitismo - ampliamente practicado en la cristiana Europa medieval-, al atribuir al pueblo judío el carácter de pueblo deicida, pueblo que elige a Barrabás ante Pilatos y consecuencia necesaria en la medida que hacían divino a Jesús. Estos contrastes y la propia crítica lógica y científica de los textos evangélicos, llenos de contradicciones entre sí y con la realidad histórica atestiguada por las fuentes externas, han llevado a no pocos estudiosos a cuestionar la historicidad de buena parte de los relatos evangélicos desde posiciones muy diversas. En este proceso, la temprana constatación de la interpolación llevada a cabo en Josefo (18, 63-64) por los copistas cristianos y, en consecuencia, la asombrosa ausencia, total y sin fisuras, de referencias históricas coetáneas dentro y fuera de la actual Palestina, a la figura de Jesús, autor según los evangelios de tantos milagros, constituye un hecho desconcertante que constituye quizá el mayor enigma del Cristianismo y llevaría a un deísta como Voltaire a sugerir irónicamente que era obra de la Divina Providencia destinada a poner a prueba la fe de los creyentes (Voltaire, 1764). Diversas interpretaciones de base científica sobre la realidad histórica de Jesús y su movimiento pueden verse en Renan 
(1863), Kautsky (1908), Schoenfield (1965), Arnheim (1984) o Mordillat et Prieur (1999). No son pocos los que piensan que el Jesús histórico simplemente no existió (Vid. p.e. Fabris, 1983 o Herencia Cristiana, 2003). El hallazgo en 1946-47 de los manuscritos del Mar Muerto del siglo II a.C. en unas cuevas cercanas a las ruinas de Qumran, ha servido en cualquier caso para cuestionar aun más la «historia oficial» de la Iglesia sobre el Cristianismo, al ligarlo doctrinalmente a los Esenios, verdaderos creadores no solo de ritos como el bautismo o la comunión, sino de conceptos clave como el amor al prójimo hasta la abnegación fuera cual fuera su tierra (Shanks, 1998), conceptos inexistentes en la endogámica moral nacional del AT. En definitiva, unos elementos críticos a tener muy en cuenta a la hora de evaluar textos mucho más antiguos como los del AT.

Solo el AT es relevante para la historia de la Ciencia, especialmente su primera parte, el Pentateuco - la Torah judía_, que consta de cinco libros. Estos libros son: Génesis, Éxodo, Levítico, Números y Deuteronomio. Supuestamente fueron escritos por Moisés, un profeta cuya existencia histórica ponen en duda hoy los propios historiadores judíos (Finkelstein \& Silberman, 2001). La autoría del Pentateuco por Moisés, ya había sido puesta en duda por el obispo abulense Alonso Tostado (1400-1455) puesto que en el último libro, el Deuteronomio $(34,5)$, se expone la muerte del propio Moisés. En realidad, tanto el Deuteronomio como los seis libros siguientes - de Josué a Reyes 2, libros clave de la historia hebraica antigua - parece fueron escritos por Jeremías y Baruc entre el 622 a.C. y el 587 a.C., en la corte del rey Josías, monarca del reino meridional, Judá cuando, casualmente, se descubrió en el templo un Libro de la Ley hasta entonces desconocido interpretando la historia en función de los intereses expansionistas del presente (Friedman, 1987; Finkelstein de Silberman, 2001). Todo esto cuestiona la historicidad, y por tanto la legitimidad de origen divino de aspectos centrales del judeo-cristianismo como los Diez Mandamientos. Unos mandamientos que han creado polémica en EE.UU. en agosto de 2003 tras ordenar un juez federal a la Corte Suprema de Alabama la retirada de un monumento a los mismos de la sede de la Corte por su carácter inconstitucional dada la no confesionalidad del país, decisión que no fue acatada por su promotor, el propio presidente de la Corte, apoyado por fundamentalistas cristianos y finalmente destituido.

El AT es el principal producto cultural del pueblo hebreo universalmente conocido, un conjunto de textos que fundamentan una religión nacional, básicamente excluyente y endogámica, sin afán proselitista hacia otros pueblos «no elegidos», en la cual moral, literatura e historia están estrechamente interconectadas en un sistema de legitimidad política teocrático. El AT contiene alguna de las más bellas páginas de literatura moral que se han producido, como el Eclesiastés («predicador» en griego), o místico-amorosa, como el Cantar de los Cantares, cuya traducción al castellano en el XVI costara al gran poeta Fray Luis de León cinco años de cárcel. El AT describe el continuado esfuerzo impulsado desde la casta sacerdotal hacia el monoteísmo, en lucha con el politeísmo del propio pueblo hebreo - recuérdese p.e. el becerro de oro-, politeísmo potenciado por las otras culturas cananeas de los valles irrigados. El AT jugó, pues, un papel cohesionante de un pueblo pastor-agricultor - las doce tribus-, papel que retomaría el Corán, el más puro monoteísmo, con las tribus nómadas árabes en el siglo VII—, en su aspiración a todo el territorio cananeo, la «tierra prometida», Canaán, para su transformación en pueblo cananeo con Estado territorial. Por tanto, la religión fue el principal elemento de identidad para el pueblo hebreo, reflejo de la realidad geográfica diferenciada de Canaán entre tierras altas y valles. Probablemente, el desencadenante del proceso de unificación de las ciudades —estado cananeas con David en el siglo XI a.C. fue la invasión de los «pueblos del mar», los filisteos ca. 1200, poseedores de la tecnología del hierro de cuyo nombre se deriva Palestina, que llega a constituir un Estado a fines del Segundo Milenio 
a.C., hasta su expulsión de Palestina en el 70 tras sucesivas revueltas contra los romanos que llevaron a Tito a destruir Jerusalén; este papel, aun más fuerte, continuaría durante la Diáspora. Hoy, Israel, cuenta con judíos de todas las ideologías y creencias, no pocos críticos con sus creencias tradicionales, y el monoteísmo dominante en Oriente Medio es el islámico, mucho más abierto, proselitista y numeroso.

La única razón para que la excluyente y endogámica religión de este pequeño pueblo de destino trágico, incapaz a pesar de las reiteradas e incumplidas promesas de Yahvé de consolidarse como Estado hace más de 2.000 años y en guerra prácticamente desde hace más de 50, llegara a tener influencia en la emergencia de la Geología y otras ciencias, fue la adopción de los textos hebreos como textos sagrados por la nueva religión, el Cristianismo. Surgida ésta en el Imperio Romano y creación en buena medida de Pablo de Tarso (Arnheim, 1984), tras el colapso imperial en Occidente llegaría a ser la principal religión en Europa, como eco cultural romano de identidad común junto al latín y el Derecho en un mundo fragmentado por el feudalismo medieval. La Ciencia moderna surgió en Europa a partir del Renacimiento en los siglos XVI-XVII. La Iglesia católica, que se fragmentaría tras la Reforma que arranca en 1517 con las 95 tesis contra la venta de indulgencias que Lutero coloca en la iglesia del castillo de Wittenberg, tenía un enorme poder del cual el presente, en Estados no confesionales, no es sino un pálido reflejo. De un lado, era la principal institución económica, el principal terrateniente en un mundo agrario, gracias a un sistema recaudatorio propio, los diezmos y las primicias, paralelo al de las monarquías y complementado por donaciones reales y nobiliarias. De otro lado, con una organización que llegaba al último pueblo y presidía la vida cotidiana a toque de campana en un grado aun mayor que sucede hoy en la mayoría de los países islámicos, su influencia política era enorme al legitimar las monarquías absolutas de su época. Este doble poder, patente p.e. en las catedrales góticas, obras de arte y manifestación de riqueza y poder sin igual en su tiempo, condicionó significativamente el desarrollo científico, básicamente retrasándolo.

El pueblo hebreo emerge, pues, a nivel histórico, a fines del Segundo Milenio a.C. como pequeño pueblo tribal, diferenciación en el propio pueblo cananeo formada por los ganaderos y agricultores extensivos de las zonas mesetarias y montañosas frente a los cananeos de los valles, con agricultura de riego (Finkelstain \& Silberman, 2001) entre dos grandes imperios de la época, el Egipcio y el Asirio, con Estados mucho más antiguos. La lengua hebrea está relacionada con el acadio, hablado por los babilonios, en el actual Irak. La Biblia describe el establecimiento en Canaán, (gran parte de Siria y Palestina), supuestamente tras crueles guerras de exterminio, auténticos genocidios aprobados por Jahvé según la Biblia como la toma de Jericó («y pasaron a cuchillo <los hebreos> a todos cuantos había en ella, hombres y mujeres, niños y viejos», Josué, 6, 21), guerras hoy cuestionadas en cuanto a su historicidad por los propios historiadores judíos, (Finkelstein \& Silberman, 2001). Incluso durante los tiempos prósperos de Salomón (ca. 970-931 a.C.), Jerusalén, la capital religiosa y política, no tenía más allá de 0,60 kilómetros cuadrados y 15.000 habitantes (Finkelstein \& Silberman, 2001), el equivalente a una pequeña ciudad provinciana en cualquiera de los tres imperios de la época. Tras David, su hijo Salomón, con la exigencia de fuertes tributos, provocaría la secesión, triunfante a su muerte, que acabaría partiendo el reino en dos: Israel al norte y Judá al sur (incluyendo éste Jerusalén, la capital del Templo). Un hecho capital para el futuro del pueblo hebreo y para el origen de la Biblia, ya que cada Estado generaría una tradición religiosa diferente. Divididos, Israel, mayor, más próspero y abierto, con mar, sería conquistado por los asirios en 722 a.C. En 587 a.C., Judá, que durante 135 años sería el foco de la cultura y religión hebrea a través del Templo de Jerusalén, cada vez más judías, fue a su vez conquistado por Nabucodonosor II rey de los babilonios, a los que el rey persa Ciro el Grande derrotaría en 538 
a.C. liberando a los cautivos judíos. Cautiverios y exilios forzados por la derrota, favorecerían el contacto con otras culturas, la apropiación de mitos ajenos reinterpretados, y, por tanto, el sincretismo ${ }^{2}$ del propio judaísmo, que dista ampliamente de responder a una tradición propia (Vid. p.e. Greenberg, 2000 para un análisis de la Biblia desde la Mitología comparada).

Solo con los Reyes (siglo XI a.C.) comenzó a registrarse en forma escrita la historia hebrea, dos mil años después que en Egipto o Mesopotamia.

El análisis científico de textos realizado durante los siglos XVIII y, especialmente, XIX, la exégesis independiente, llevó tras arduos trabajos a la «Hipótesis Documental»: la existencia de cuatro fuentes diferentes de documentos y tradiciones mezclados en el Pentateuco. De acuerdo con —Friedman (1987) y Finkelstein \& Silberman (2001) éstas serían la J (de Jahvé o Jahvista, escrita entre 848 y 722 a.C. para el primer autor, y en el VII a.C. para los segundos en el reino de Judá); la E (de Elohim, otra forma de designar al ser divino, plural y politeísta, escrita en el reino de Israel); la P o S (de Priestly, Sacerdotal, escrita en la época del rey de Judá, Ezequías, ca. 726-609 a.C.), y la D (Deuteronómica, escrita en la época del rey Josías probablemente por Baruc y el profeta Jeremías, ca. 622609 a.C.). Tanto E como D fueron obra de los sacerdotes mosaicos de Silo, centro religioso nacional en tiempos de Samuel, sacerdotes levitas desplazados por los aarónidas, davídicos, en tiempos de Salomón que pasarían a controlar el Templo de Jerusalén; este conflicto en el seno de la clase sacerdotal, en que se ventilaban los diezmos y primicias, explica parte importante de la historia de la primera Biblia, el Pentateuco y los siguientes seis libros de la Biblia, su núcleo duro (Halpern, 1981). J y E fueron combinadas en un solo texto tras la conquista del reino de Israel por los asirios en 722 a.C. para dar soporte religioso conjunto a la población de Judá, que albergaba numerosos huidos del Israel conquistado, antes de P, reacción en JE (Friedman, 1987).

La reunión de las diferentes versiones en una sola fue llevada a cabo probablemente, según Friedman (que denomina fuente R, Redactor, al autor o autores de la versión final del Pentateuco), por el sacerdote aarónida y legislador judío Esdras —al que el emperador persa Artajerjes otorgó autoridad sobre Judá- posteriormente al 458 a.C., ochenta años después de la liberación de los cautivos judíos en Babilonia por Ciro el Grande, con objeto de unificar religiosamente a Judá, entonces provincia del Imperio Persa. Debido a la conservación en un único texto de todas las versiones, probablemente buscando un consenso ecléctico entre las diversas corrientes de tradición, frecuentemente opuestas, se ha constatado la existencia de numerosas contradicciones, los llamados «dobletes». Esta hipótesis ha sido complementada y confirmada por pruebas arqueológicas y análisis comparativos históricos y mitológicos (Finkelstein \& Silberman, 2001; Greenberg, 2000). Como puede verse, la construcción de un único texto para el AT, siguió un proceso muy diferente que en el caso de los cuatro evangelios canónicos del NT, elegidos directamente por el Espíritu Santo de entre todo el conjunto de evangelios que por entonces circulaban, a través de un milagro en el curso del Concilio de Nicea de 325. El milagro operado por el Espíritu Santo según la tradición, consistió en hacerles subir desde el suelo en que se habían colocado hasta el altar, hecho que sucedería por la noche, quedando los que no se habían movido como apócrifos (González-Blanco, 1934). La falta de mezcla, ha facilitado el análisis crítico de los textos evangélicos.

El problema de la fiabilidad histórica, de la historicidad de los textos del AT puede ser comprendido comparando la distancia temporal de la compilación respecto al origen oral de las fuentes — de siglos a un milenio—, con la de los diferentes evangelios, canónicos y

2 Sincretismo: doctrina o sistema que trata de conciliar o armonizar ideas o teorías diferentes u opuestas. 
apócrifos, con importantes divergencias entre sí y con la realidad histórica tal y como se indicó más arriba. El primero, el de Marcos, fue compuesto tan solo algo más de treinta años tras la muerte de Jesús, un intervalo que parecería breve para una transición de la realidad histórica al mito. Arroja luz sobre como se crean históricamente las leyendas ver p.e. el caso de otra figura con proyección legendaria, Rodrigo Díaz de Vivar, El Cid (ca. 1049-1099), quizá el «héroe» más importante de la historia española y el de mayor proyección universal, fruto de la época de los reinos de taifas a los que protegió primero como mercenario valeroso y hábil y al final señor de la guerra de Valencia en la época almohade. Su referencia épica popular —en cierto modo un paralelismo laico a lo que son los relatos evangélicos-, El Cantar de Mío Cid, compuesto unos cuarenta años tras su muerte recogiendo tradiciones orales, está tan lleno de falsedades históricas — como la de la jura de Sta. Gadea o las batallas ganadas después de muerto-, que ha tenido que ser completamente marginado a la hora de obtener una visión realista, científica, del Cid histórico, posible en este caso por la existencia de testimonios escritos coetáneos tanto musulmanes como cristianos (Martínez Díez, 1999), algo imposible como vimos en el caso de Jesús, en el que pudiendo reconstruirse el ambiente histórico, no puede reconstruirse con un mínimo rigor histórico su biografía, el «Jesús histórico».

La invención que vierte la imaginación popular en la tradición oral es casi increíble, como prueba p.e. la leyenda del ardacho, un caimán disecado que trajo de América fray Tomás de Berlanga, descubridor de las Islas Galápagos en 1535, y que se encuentra en la colegiata de Berlanga de Duero, en Soria. Tal y como refiere el escritor Ramón Carnicer, la creencia popular, una vez olvidado quizá su origen, es que se trata de un lagarto al que

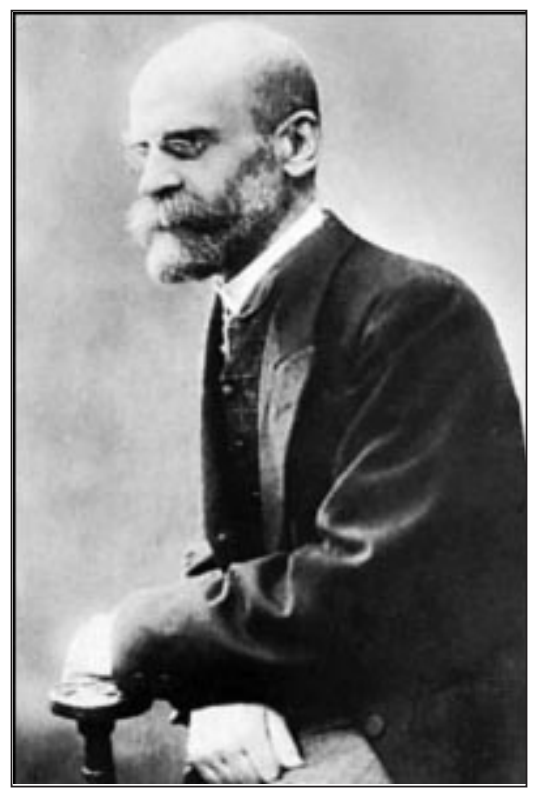

FIgURA 2. Émile Durkheim (1858-1917) uno de los padres de la Sociología, sentó las bases para el análisis científico de la génesis social y las funciones sociales de las religiones, aplicables al Judaísmo y el Cristianismo que tienen en común el Antiguo Testamento como libro sagrado. 
un pastor alimentaba con leche, y que se aficionó a comer cadáveres por lo que creció mucho y hubo que matarle. La imaginación sustituyendo la verdad olvidada. ¿Cuántas veces ha funcionado una lógica similar en la creación de leyendas y mitos?

Otras veces, la credulidad popular, expresión evidente de una necesidad humana, crea los propios milagros. Así ha sucedido p.e., en contra de testimonios escritos y decisiones formales de la propia Iglesia católica, con el llamado Santo Sudario de Turín, que supuestamente habría envuelto el cadáver de Jesús, una reliquia fabricada en el siglo XIV por un pintor envolviendo una imagen de madera convenientemente untada de pintura que adquiriría fama en el contexto de la Europa devastada por la Peste Negra de 1347-1350, desesperada y hambrienta de reliquias a las que suplicar que parara la devastación, lo que generó una auténtica industria (Arnheim, 1984). Pierre d'Arcis, obispo de Troyes, Francia, dijo por escrito en 1389 que «Dicha tela había sido pintada astutamente, siendo la verdad certificada por el artista que la pintó»; ello llevo al papado a declarar falsa la supuesta reliquia (Arnheim, 1984; Mordillat y Prieur, 1999). Recientemente, en 1988, pruebas de C-14 han dado para el lienzo una edad media del siglo XIV (1260-1390), como era esperable; un resultado que imposibilita que el lienzo sea el sudario de Jesús. Todo ello no ha impedido el culto a la supuesta reliquia, carente de coherencia antropométrica y con la costumbre judaica de utilizar varios lienzos para el amortajamiento, en contra de toda evidencia racional. La Iglesia católica, prudentemente, ha remitido a la Ciencia para su autenticidad.

El reconocimiento de falsificaciones está en la propia Biblia. Así, Jeremías $(8,8)$ dice: «¿Cómo decís:»Sabios somos; poseemos la Ley de Yahvé. «¿Más he aquí que la plama mentirosa de los escribas la ha convertido en mentira». Sin duda debía conocer el tema, ya que sus escritos profetizando la destrucción de Jerusalén y la cautividad en Babilonia se realizaron trás haber sucedido en 587 a.C. (Friedman, 1987).

Así que la omnipresencia de la tradición oral, la milagrería y las falsificaciones en el texto bíblico, conocidas, pues, las probadas incertidumbres sobre la veracidad histórica de estas tradiciones y las enormes distorsiones que sufren a lo largo del tiempo en función del olvido o del interés político (caso del Deuteronomio con Josías p.e.), plantea no solo el a menudo insoluble problema de separar invención y realidad, sino el arduo problema teológico de cómo y cuando se produce y conserva en ella la inspiración divina, especialmente teniendo en cuenta las palabras citadas de Juan Pablo II en las que afirma respecto a la Biblia que Dios no solo la inspiró, sino que «La pronunció a través de los hagiógrafos». Los investigadores de los dos últimos siglos han arrojado mucha luz sobre la historia del AT y el pueblo hebreo, existiendo en la actualidad serias dudas acerca del carácter histórico de relatos bíblicos claves en lo doctrinal como los de los patriarcas, el Éxodo desde Egipto, la historicidad de José y Moisés, la conquista de Canaán y la verdadera realidad de los reinados de David y Salomón (Finkelstein \& Silberman, 2001).

La falta de historicidad de capítulos clave del AT, especialmente en el Pentateuco, no puede sino plantear dudas sobre la veracidad de otras afirmaciones que en él se contienen, en particular las que conciernen a temas propios de la Ciencia, dudas que el análisis confirma ampliamente como veremos. Sin embargo, para muchas personas y para las jerarquías religiosas correspondientes - judías, católicas y protestantes y, en parte, musulmanas-, la Biblia se ve como fruto de inspiración divina y, por tanto, se tiende a creer en la veracidad y el carácter histórico de lo que relata. Un problema presente en todas las religiones reveladas, que inevitablemente aspiran a la historicidad al situar su Revelación, y por tanto su doctrina, en el espacio y el tiempo, en la Geografía y la Historia. Examinaremos a continuación, desde la razón científica — las religiones tienen múltiples funciones sociales (de integración y asistenciales p.e.) que responden a su carácter de hecho social 
(Durkheim, 1914), y psicológicas, que no son objeto de este artículo—, la consistencia científica y posible trama geológica y geográfica de algunos relatos bíblicos particularmente importantes en el desarrollo científico.

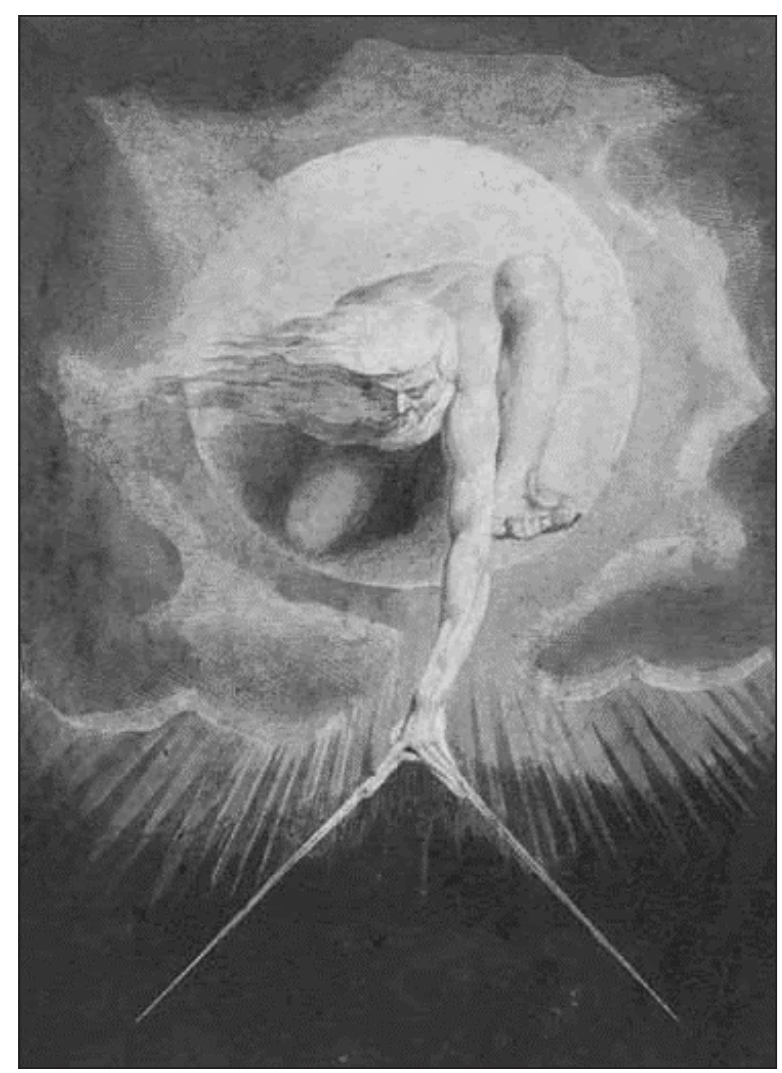

Figura 3. La Creación en The Ancient of Days, según el pintor y poeta William Blake (1757-1827), obra de un Dios personal, antropomórfico, como el bíblico.

\section{La creación: dos relatos antievolucionistas científicamente incorrectos}

La Creación es descrita en el Génesis 1 y 2. Este libro, expone la Cosmología, la Geología y la Paleontología bíblicas y señala, a través del relato sobre el Paraíso y el supuesto «pecado original», una Geografía bíblica claramente situada en Mesopotamia, no en Palestina (Gén. 2, 14).

Los expertos bíblicos han mostrado la coexistencia en este texto de dos fuentes diferentes (Friedman, 1987). La primera, la J, aparece en Gén. 2,4 b-25; la segunda, la P o S, va de Gén. 1, 1 a 2, 3. La Mitología comparada ha mostrado claras influencias de relatos egipcios y mesopotámicos anteriores (Greenberg, 2000). Por ejemplo, el error de 
que las plantas sean creadas el tercer día (Gén. 1, 11-12), antes de que fuera creado el Sol, fruto del cuarto día, Gén. 1, 16, (con lo cual hubieran carecido de energía para realizar la fotosíntesis, condición necesaria de su existencia), viene probablemente del egipcio Libro de la Muerte.

El relato de la fuente PÓS tiene evidentes paralelismos con el Enuma Elish mesopotámico, que data de ca. 2000 a.C. (Heidel, 1951).

Hay otros errores obvios desde el mero sentido común. Así, tras ser creadas la luz y las tinieblas $(1,4)$, se dice en 1, 5: «A la luz llamó día, y a las tinieblas noche: y así de la tarde aquella y de la mañana siguiente, resultó el primer día». Como todos sabemos, es el Sol en su movimiento aparente alrededor de la Tierra el que da origen al día y la noche, la mañana y la tarde, en nuestro planeta; cuando el Sol se ha puesto, lo que hay es noche. Pero el Sol no es creado sino en el cuarto día $(2,16)$. Podría pensarse que en realidad el texto se estuviera refiriendo a otro tipo de día, no al solar o natural, pero los elementos definitorios son diferentes, tanto del día astronómico (tiempo comprendido entre dos pasos consecutivos del Sol por el meridiano superior), como del día sidéreo (tiempo siempre igual que tarda la Tierra en dar una vuelta entera alrededor de su eje polar; 3'56" más corto que el solar medio).

Por otra parte, de acuerdo con la teoría cosmológica del Big Bang, la Gran Explosión, muy al comienzo del mundo solo había luz que llenaba todo el espacio-tiempo creado por la probable fluctuación cuántica que dio origen a la Gran Explosión inicial (Díaz Pazos, 2003).

En 1, 2, puede leerse: «La tierra, empero, estaba informe y vacía, y las tinieblas cubrían la superficie del abismo: y el Espíritu de Yahvé se movía sobre las aguas». Pero según la Cosmología moderna la Tierra se formó por acreción gravitacional de cuerpos menores, primero polvo cósmico, después planetesimales, tras la formación del Sol - y no antes y al principio como dice el Génesis, base del erróneo geocentrismo bíblico—, siendo entonces caliente y con una corteza llena de violentas erupciones volcánicas (Anguita, 1988), y por tanto con menos tinieblas que hoy. Por otra parte, el agua, al contrario de lo afirmado, no existía en estado líquido, sino vaporizada.

En 1, 7, se dice: «E hizo Yahvé el firmamento, y separó las aguas que estaban debajo del firmamento, de aquellas que estaban sobre el firmamento». Aquí está la errónea explicación bíblica de la lluvia, que origina p.e. el Diluvio («se abrieron las cataratas del cielo», 7, 11): la caída del agua que está sobre la bóveda celeste, más allá de las estrellas, y no en las nubes como es en realidad; para los hebreos el mundo estaba rodeado de agua (Ibarreta, 1987).

En 1, 11 puede leerse en el tercer día: «Produzca la tierra yerba verde», y en 1, 21, para el quinto día: «Crió, pues, Yahvé, los grandes peces, y todos los animales que viven y se mueven». En realidad, como muestra la Paleontología, las plantas terrestres surgieron al final del Silúrico, hace unos 420 millones de años, y las primeras praderas de herbáceas no surgieron hasta el Oligoceno ( $\mathrm{de}-40$ a -25 millones de años), apareciendo las gramíneas, base de las grandes praderas, en el Mioceno (-25 a -11 millones de años), mucho después, por tanto, que los peces, ya existentes desde fines del Cámbrico, hace unos 520 millones de años, y no antes como afirma el Génesis.

En Gén. 1, 25 se dice en el sexto día, aunque refiriéndose al anterior: «Hizo, pues, Yahvé, las bestias silvestres de la tierra según sus especies». Por tanto, cada especie viva fue creada como tal. Esta es la base justificativa de las pasadas y actuales corrientes creacionistas, completamente anticientíficas de acuerdo con de lo que han mostrado exhaustivamente la Paleontología y el evolucionismo.

El relato, caracterizado por la sucesiva intervención divina para crear cada realidad importante, en la línea providencialista de un Dios personal, antropomórfico, que vela e 


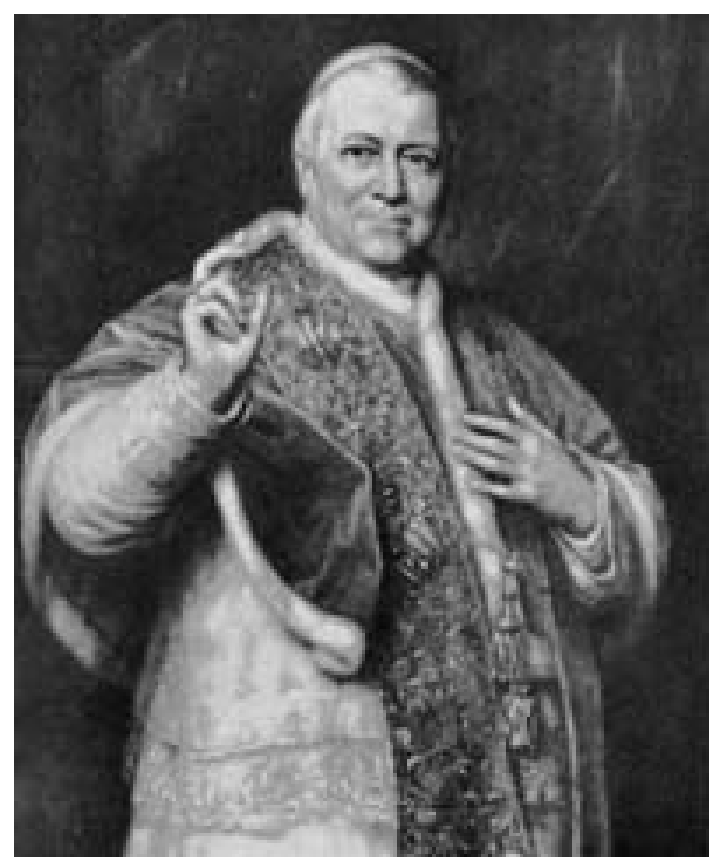

Figura 4. En 1864, tras la publicación del Origen de las especies en 1859, y el avance de las Ciencias Bíblicas, el papa Pío IX condenó en su carta-encíclica Syllabus errorum, el racionalismo, la ciencia moderna, las sociedades bíblicas, el liberalismo y la libertad de expresión e investigación. En 1870, el Concilio Vaticano I declararía dogma de fe católico la infalibilidad papal.

interviene continuamente en la marcha del mundo, está en las antípodas de lo que la Ciencia nos transmite de proceso unitario, universal, autosostenido y necesario, en términos probabilistas, de la materia-energía tras la fluctuación cuántica del vacío que probablemente generó nuestro Universo y el espacio-tiempo (Díaz Pazos, 2003). Un proceso autosostenido que se mueve por su propia dinámica, configurando progresivamente en el tiempo las sucesivas realidades emergentes, primero los procesos geológicos y después la vida, que evoluciona en adelante a través de la mutación aleatoria del material genético y la selección natural por el ambiente, generando la enorme biodiversidad existente. Proceso, por otra parte, inacabado, en contra de lo que dice el relato, ya que la evolución prosigue bajo nuestros ojos (Ayala, 1994), y, por tanto, no se ha cerrado con el descanso bíblico del séptimo día.

Debe señalarse que en el mundo de hace pocos siglos, carente de una concepción como la actual sobre la enorme amplitud de la historia del Universo, con una edad mayor de 13.000 millones de años, mundo agrario en el que no poca gente ni tan siquiera a fines del XIX en España conocía con exactitud su propia edad (de Miguel, 1998), la explicación bíblica era relativamente verosímil para el sentido común de la época, mientras que la evolucionista, aún no estaba ni formulada, al igual que lo era el supuesto movimiento del Sol en torno a la Tierra, conforme con los datos inmediatos observados. Ciencia y sentido común no son siempre equivalentes (Hempel, 1966). No debe sorprender, por tanto, el crédito que mucha gente, en un mundo agrario y analfabeto (en España p.e. casi los dos 
tercios de la población eran analfabetos en 1900), concedía a las tesis bíblicas, arropadas además por la enorme organización eclesial que llegaba al último pueblo. Por eso fue tan importante el concepto del tiempo geológico y tan ardua la lucha que tuvieron que librar los primeros geólogos en medio de la incomprensión y el rechazo.

Eclosionada la visión científica, el reconocimiento progresivo de estos errores e inconsistencias bíblicas con la Ciencia, obligó a un número progresivo de teólogos a abandonar a lo largo del XIX una interpretación literal de los textos bíblicos en los aspectos verificables empíricamente — históricos y científico-naturales - para evitar el choque con la Ciencia positiva. Al principio, algunos trataron de mostrar que había coincidencia entre los relatos bíblicos y los nuevos hallazgos de la Ciencia, p.e. entre los días de la Creación y las eras geológicas; después, simplemente se abandonó en la mayor parte de los casos —especialmente entre los católicos-, cualquier intento de conciliación entre razón científica y creencia bíblica, cada vez más divergentes allí donde coincidían. Se instauró así progresivamente un pensamiento esquizofrénico para muchos expertos cristianos que renunciaron a dar el salto de la credulidad que suele caracterizar la creencia a la racionalidad científica: una lógica para hacer ciencia, basada en la realidad, otra para las bases históricas y científicas de su creencia, dirigidas progresivamente hacia un terreno irreal, hacia una fe progresivamente desencarnada de lo real, sustancial por tratarse de unas religiones reveladas.

Esta disonancia razón y fe en lo empíricamente verificable - p.e. un supuesto hecho histórico o una tesis contrastable, como la del origen de la yerba antes que los peces-, allí donde la fe debe plegarse a la razón científica, fue verificándose también en aspectos doctrinales, que nunca pueden violar el Principio de Contradicción, algo muy frecuente en la Biblia. Así, p.e., Yavhé, iracundo porque en la supuesta toma de Jericó alguien no ha respetado la parte divina en el saqueo, el oro y la plata, dice a Josué «no estaré más con vosotros hasta que extermineis al reo de esta maldad» (Josué, 7, 12); en consecuencia, el autor del hecho, Acán, es lapidado. En Éxodo (20, 13), Yavhé, al promulgar el Decálogo, había ordenado «No matarás» ...lo cual no impidió inmediatamente a continuación la matanza de los idólatras que habían vuelto al becerro de oro: «Esto dice el Señor Dios de Israel: Ponga cada cual la espada a su lado (...) y cada uno mate aunque sea al hermano, y al amigo, y al vecino. Ejecutaron los levitas la orden de Moisés y perecieron en aquel día como unos veinte y tres mil hombres. Y Moisés les dijo: Hoy habeis consagrado vuestras manos al Señor, matando cada uno con santo celo aun al propio hijo y al hermano, por lo que sereis benditos» (Éxodo, 32, 27-29). Sin duda un ejemplo de coherencia doctrinal que debería dejar algo perplejo al creyente, al que se ordena primero no matar — por una deidad que previamente ha exterminado a todo el género humano, creado por él, en el Diluvio-, para a continuación exigirle que mate al hijo y al hermano. ¿Cabe de esto, tan frecuente en la Biblia, alguna interpretación al margen de la mera literalidad, que presenta una deidad que hace lo contrario de lo que manda? ¿A qué atenerse? ¿Se debe matar o no se debe matar?

El problema del abandono de la interpretación literal que tenga en cuenta los géneros literarios empleados en busca de la verdad doctrinal, difícilmente evitable por lo claro de los versículos y textos bíblicos en numerosos casos, es el de como encontrar en la exégesis ${ }^{3}$ un sentido alternativo claro y unívoco a los textos, una clave interpretativa, una hermenéutica ${ }^{4}$ que conserve el carácter divino de la obra, con la que todos — de católicos a baptistas

3 Exégesis: Interpretación o explicación de un texto en sus aspectos filológicos, históricos o doctrinales.

4 Hermenéutica: método de interpretación de los textos para precisar su auténtico significado y facilitar su comprensión. 
o ateos-, aplicando el pensamiento lógico basado en el Principio de Contradicción, puedan estar de acuerdo. Antes de que se cuestionara la interpretación literal no se había encontrado dicha hermenéutica admisible por todos para lo doctrinal, como prueban los múltiples cismas a lo largo de la historia cristiana, basados generalmente en la propia ambigüiedad de los textos, cuando no en la contradicción de unos con otros y aun dentro del mismo texto, fruto inevitable de su génesis oral y múltiple, en autores y tiempos. Tampoco se ha encontrado después a pesar de que Friedrich Schleiermacher (1768-1834) creara realmente la Hermenéutica para aplicarla a los estudios bíblicos en su obra publicada en 1838 , prueba de lo confuso y contradictorio del mensaje, como muestra la multiplicidad de escuelas con tesis a menudo contradictorias y que el propio autor, protestante, acabara defendiendo una concepción básicamente subjetiva de la religión. Así que, en el campo doctrinal, el problema debe ser difícilmente soluble ya que la palabra pronunciada a través de los hagiógrafos es, objetivamente, contradictoria y confusa.

Tomemos p.e., para ver lo arduo de la tarea - solo en los temas que tocan con la Ciencia-, la aparición de los sucesivos seres vivos. En Gén. 1, 25, como vimos, se indica claramente que cada especie fue hecha separadamente, idea que es remachada por las sucesivas creaciones de los diferentes seres a lo largo de la semana de la Creación; también por la creación ad hoc del hombre (Gén. 1, 26-27), y después, como si se tratara de una subespecie, de la mujer (Gén. 2, 21), como «ayuda y compañía» para el varón (Gén. 2, 18), a cuya costilla debería su existencia (Gén. 2, 22) y al relato bíblico una justificación divina de su papel subsidiario respecto al varón, de segundo sexo como diría Simone de Beauvoir. Una tesis que implica un completo desconocimiento de los inspirados autores bíblicos acerca del mecanismo genético-celular de la reproducción sexual, común para los dos géneros. La interpretación literal de este relato ha sido tan consustancial a la Iglesia católica, que p.e., Jerónimo de Barrionuevo (1587-1671), refiere en sus «avisos», cartas dirigidas al deán de Zaragoza entre 1654 y 1658, como «Entre los agustinos y trinitarios ha habido en Salamanca grandes debates, llegando a las manos (...) a bofetadas y coces en los actos públicos, sobre si quedó Adán imperfecto quitándole Dios la costilla, y si fue solo carne con lo que le llenó el hueco». Lo que sabemos de la evolución, no solo rompe la separación bíblica entre los seres vivos, que llega aquí al extremo de creaciones separadas de hombre y mujer, ya que todos estamos unidos y emparentados por el mismo material y procesos genéticos (Ayala, 1994), sino que elimina cualquier parecido con el relato bíblico en cuanto a su forma de aparición, en general gradual como sucede en el caso humano con los sucesivos homínidos. Es obvio que, en lo científico, la literalidad, difícilmente evitable o superable en lo doctrinal, llevaría a considerar a Yavhé como un perfecto ignorante si se mantiene el carácter de texto inspirado.

¿Qué bases racionales admisibles por todos pueden soportar, a partir de lo expuesto en el relato, p.e. la transmutación del texto bíblico inequívocamente creacionista y providencialista en la evolución biológica transformista y no finalista, antiprovidencialista, que la Ciencia ha probado ampliamente (Vid. p.e. Arsuga, 2001) y la Iglesia católica ha admitido recientemente en forma no científica — dirigida y finalista — próxima al evolucionismo teísta, ortogenético ${ }^{5}$, del jesuita Teilhard de Chardin? Simplemente ninguna conservando el texto. Pero, ¿qué quitar y qué conservar de él y por qué hacerlo? Ni tan siquiera dejándolo reducido a una generalización del tipo «En el principio creó Yahvé el mundo» — similar a Gén. 1, 1—, llegaría a ser compatible con la Ciencia, ya

5 Ortogénesis: Proceso mediante el cual, en una línea evolutiva, se intensifica gradualmente un determinado carácter. Cuando se aplica desde posiciones teístas al conjunto de la evolución, se hace insistiendo en el finalismo global de la misma hacia la aparición del hombre, una tesis científicamente incorrecta. 
que la fluctuación cuántica del vacío, siendo una propiedad intrínseca de la nada, deja sin lugar a un acto de creación. Pero entonces ¿por qué el empeño de los autores bíblicos, inspirados para los creyentes, en describir con afán de veracidad y verosimilitud y de forma relativamente minuciosa el proceso y la constante intervención de Yahvé como motor de cada cambio importante? ¿Por qué la insistencia en considerar obra divina un texto contradictorio y frecuentemente erróneo en lo científico? ¿Por qué el reiterado afán de la Iglesia católica, supuestamente guiada por Dios, siglo tras siglo, en perseguir a los científicos que cuestionaban el texto? Resulta de interés la reflexión del reverendo Michael Jackson sobre el tema de la Evolución, cuyos logros explicativos alaba, acerca de una posible «vía intermedia» entre el creacionismo literalista y el neodarwinismo, una «evolución guiada» por el Espíritu Santo que recuerda a las tesis teilhardianas y católicas; sin embargo, acaba concluyendo que sus ideas «no pueden ser probadas», lo que vuelve a situar en definitiva el problema fuera de los cauces racionales, en el terreno de la evolución teísta, de la fe (Jackson, 2003). Fabris (1983), ha mostrado las enormes divergencias sobre la posible realidad histórica de Jesús que la investigación de diferentes escuelas ha producido tratando de profundizar en los Evangelios más allá de lo literal.

En realidad, la raíz principal de la interpretación no literal para los aspectos científicamente verificables, parece descansar en la demostración científica de los errores del texto, y por ello eclosiona en los últimos ciento cincuenta años; durante los mil ochocientos años anteriores, la interpretación literal no era cuestionada. No parece casual que la Hermenéutica aparezca formalmente en 1838 tras la publicación en 1774-78 de fragmentos de la investigación sobre el Jesús histórico de Herman S. Reimarus (1694-1768), profundamente demoledora de la imagen tradicional al mostrar el trasfondo político antirromano del cristianismo original, que explica no pocas contradicciones de los Evangelios. Tampoco es casual la condena formulada por Pío IX de la Ciencia positiva, el racionalismo y las Sociedades Bíblicas en su carta-encíclica Syllabus errorum de 1864 (en 1859 se había publicado el Origen de las especies), así como el establecimiento en 1870 del dogma de la infalibilidad papal. Una reacción a la incapacidad de argumentar racionalmente contra los descubrimientos científicos consistente en imponer, entre los católicos, el argumento de la fe desde la autoridad absoluta. Un curioso mecanismo de toma de decisiones en una organización que lleva el nombre griego de «ecclesia», asamblea, una reunión donde las decisiones se toman colectivamente, como se hacía en la Iglesia primitiva.

Ahora bien, si hubiera resultado que el texto era literaria y científicamente correcto, ¿Hubiera surgido la interpretación no literal? ¿Se hubieran condenado la Ciencia o las Sociedades Bíblicas? ¿O, más bien, no hubiéramos asistido a una exaltación apologética del carácter divino del texto, justamente porque era científicamente correcto, y se habría defendido lo correcto de la interpretación literal? Probablemente, esto último es lo que hubiera sucedido a la luz de la utilización que se hace y se ha hecho de cualquier descubrimiento arqueológico concordante con el relato bíblico por adjetivo que fuera a la componente doctrinal para proclamar que «la Biblia tiene razón», el último, en el verano de 2003, el descubrimiento del túnel bajo Jerusalén. Esto, pone de relieve como la razón última de la interpretación no literal para lo verificable científicamente — desde la óptica cristianadescansa en una premisa implícita no científica, la de que la interpretación no literal es necesaria porque siendo el texto de inspiración divina, lo contrario llevaría a cuestionar esa inspiración al romper la omnisciencia divina. Parece, pues, dudoso, que la interpretación no literal descanse de forma suficiente sobre hipótesis científicas o epistemológicas rigurosas y universalmente admisibles. 

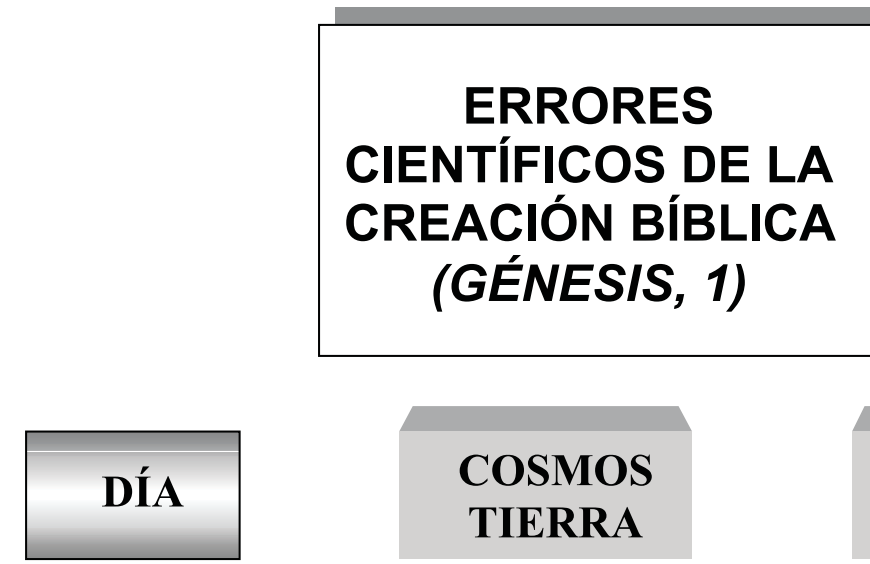

COSMOS

TIERRA

\section{VIDA}

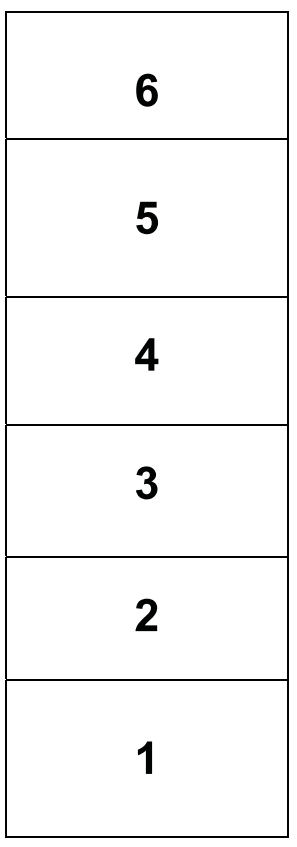

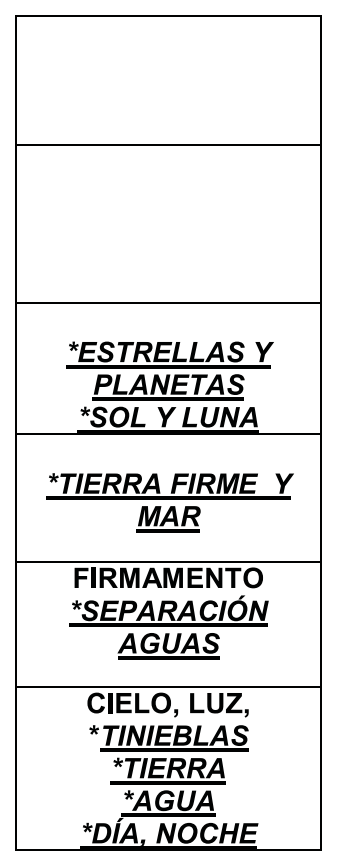

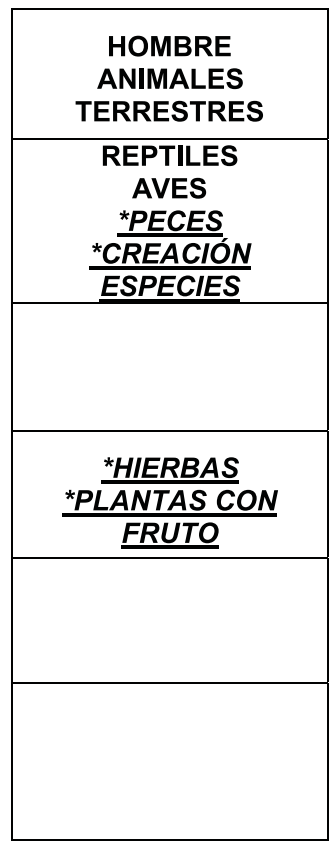

*SOL Y LUNA : ERROR ABSOLUTO O RELATIVO EN LA SECUENCIA TEMPORAL COSMOLÓGICA, GEOLÓGICA O PALEONTOLÓGICA O EN EL CONCEPTO

Figura 5. Errores científicos del relato bíblico sobre la Creación a la luz de la Cosmología, Geología y Paleontología. Al menos el 67 \% de las tesis del relato del Génesis, los dos tercios, son erróneas. 
Problemas pues, a menudo insolubles, que han ido confirmando a los no creyentes en su idea de atribuir a la Biblia un origen estrictamente humano —el de obra de un pueblo precientífico hijo de su tiempo y su lugar que busca un sentido a las grandes preguntas y un fundamento a una moral y una política-, y que coloca a los creyentes críticos, racionalistas, ante esa misma disyuntiva para no tener que admitir equivocaciones y contradicciones divinas, algo incompatible con la infinita sabiduría que se supone está en la esencia de la Divinidad en que creen.

El o, mejor, los dos relatos del Génesis sobre la Creación, no pueden juzgarse desde criterios de historicidad como los del Diluvio o Sodoma y Gomorra, ya que se refieren a supuestos hechos que, justamente, fundan la propia Historia, del Universo y humana. Por tanto, debemos juzgar la veracidad de las tesis que contienen. Tal y como puede verse en la Figura adjunta, si se tiene en cuenta que hay al menos otras dos tesis bíblicas más contenidas en el relato, la ausencia de extinciones y la enorme cortedad del tiempo cosmológico, de un total de veintiuna tesis contenidas en el relato de la Creación, catorce son erróneas o falsas; por tanto, el 67 \% de las tesis bíblicas sobre la Creación contenidas en Génesis, 1, los dos tercios, son científicamente erróneas o falsas.

El relato, además, es muy incompleto tanto en la evolución cosmológica como en la geológica o biológica. En definitiva, y en contra de lo que afirma un libro apologético popular en los medios cristianos (Keller, 2000), en numerosos aspectos claves, científicos e históricos, la Biblia, simplemente, no tiene razón, y, en realidad, cuanto más avanza el conocimiento científico, histórico y arqueológico, los datos sugieren más bien que cada vez va teniendo menos.

Toda la Biblia es, además, rehén de una concepción geocéntrica, no ya del Sistema solar sino del Universo. Una concepción coherente con su carácter de obra de un pueblo precientífico y con su época, y única que podía soportar la idea de que en un Universo con miles de millones de galaxias, en una galaxia singular, la Vía Láctea, la nuestra, el Dios Creador del Universo fuera a designar como «pueblo elegido» (¿elegido para qué?) a uno de los más pequeños pueblos de un planeta perteneciente a uno de los cien mil millones de estrellas que componen la galaxia. Una concepción provinciana si se la compara con la grandiosidad de las modernas ideas cosmológicas en las que nuestro mundo, probablemente surgido de una fluctuación cuántica del vacío, podría formar parte de un cuasiinfinito conjunto de Universos (Díaz Pazos, 2003). ¿No es la narración bíblica una desmesura cósmica a la luz de nuestros conocimientos? ¿No sería el carácter de «pueblo elegido», desde la razón histórica y sociológica, más bien una coartada proporcionada por la casta sacerdotal para justificar la apropiación por la fuerza hasta el genocidio de una tierra ya ocupada por otros, la «tierra prometida», Canaán?

La otra alternativa es la del actual Creacionismo o «Ciencia» de la Creación, movimiento cristiano de raíz protestante especialmente fuerte en EE.UU. y claramente volcado hacia la intervención política — desde su creencia en ser el nuevo «pueblo elegido» de la nueva Canaán, EE.UU., tierra de promisión—, actividad política objetivamente compartida con las potentes organizaciones católicas conservadoras en España o América Latina. Este movimiento acepta, en una forma en principio más coherente en lo doctrinal que el catolicismo, la interpretación literal de la Biblia. Esto, dadas las obvias contradicciones con la Ciencia como las presentadas, le lleva necesariamente a tratar de demostrar que ésta, la Ciencia, abiertamente crítica con las implicaciones, supuestos y relatos bíblicos, está equivocada, y que la Biblia, literalmente entendida, tiene razón (Vid. p.e. Creation Science and Earth History, 2002 y Faith \& Reason, 2002), un callejón sin salida. Según los autodenominados creacionistas científicos, las técnicas radiométricas de datación son erróneas; el campo magnético de la Tierra prueba que ésta no tiene más de 10.000 años; los 


\section{CRONOESTRATIGRAFÍA DEL CREACIONISMO CIENTÍFICO}

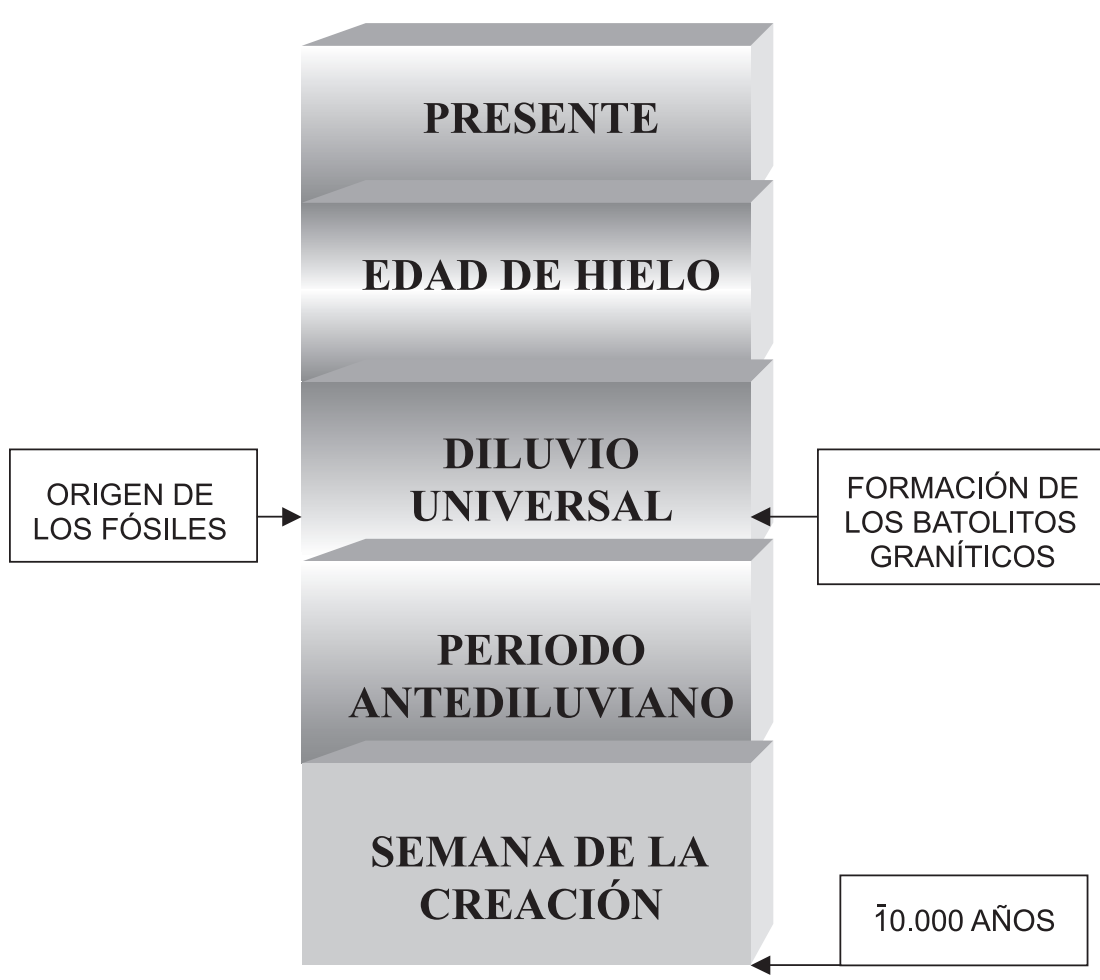

FIgura 6. Escala cronoestratigráfica del Creacionismo Científico de acuerdo con el relato bíblico. Obsérvese la baja edad del Universo: 10.000 años.

batolitos graníticos se originaron durante el Diluvio Universal en 150 días; los Andes se alzaron tras el Diluvio por rebote isostático ${ }^{6}$; la Tierra prediluvial era plana (una idea tomada de Burnett, Vid. Sequeiros 2000) y, obviamente, la evolución biológica de las especies es una falacia. Los creacionistas tienen su propia escala cronoestratigráfica con cinco grandes períodos que comienzan con la Semana de la Creación y llegan al Presente tras pasar por los períodos Antediluviano, el Diluvio Universal y la Edad de Hielo. Según

6 Rebote isostático: Levantamiento del terreno en el periodo postglacial, posterior a la fusión del hielo que lo cubría debido a un reajuste isostático de bloques a consecuencia de la pérdida de peso al desaparecer el hielo. 
Froede \& Reed (1999) se trata de: «Un esquema alternativo que se distingue por la prioridad de la revelación sobrenatural». Sin duda. El problema, es que esto no es ciencia, sino creencia, religión.

Lógicamente, pues, para Bruce Alberts, presidente de la Academia Nacional de Ciencias norteamericana, la Ciencia de la Creación «no está referida a causas naturales y no puede ser sometida a tests con significación, no estando, por tanto, constituida por hipótesis científicas. En 1987 la Corte Suprema de los EE.UU. sentenció que ese creacionismo es religión, no ciencia, y no puede ser defendido en las escuelas públicas». En Numbers (1992), puede verse una historia del creacionismo «científico» y en Plimer (1992), una exposición de la polémica con los científicos.

Una de las posiciones posibles ante la disonancia fe-razón es el «Credo quia absurdum», creo porque es absurdo, de Tertuliano; otra, la mantenida acerca del Diluvio Universal bíblico en el XVIII por Castel o Buffon en el sentido de que se trataba de un acto sobrenatural de la voluntad divina, un hecho excepcional que no podía ni debía explicarse científicamente (Pelayo, 1996). Descartadas estas posiciones, que remiten a la primacía y exclusividad de la fe respecto a la razón científica para escamotear el problema, tras la evidencia de los múltiples errores científicos del relato bíblico, científico-naturales e históricos, se ha ido abriendo un dilema para cristianos y judíos. Su planteamiento es el siguiente: si se acepta la interpretación literal de los textos inspirados, hay que intentar demostrar, como los creacionistas «científicos», que la Ciencia está equivocada (intento desesperado y a la postre vano), ya que si no, Yahvé estaría equivocado y, por tanto, no sería Dios; si, al contrario, se abandona la interpretación literal y se aceptan los sucesivos descubrimientos científicos, se abandona la misma posibilidad de una interpretación única, unívoca y sin posibilidad de confusión, que cumpla con el Principio de Contradicción (que algo no pueda ser y no ser al mismo tiempo y en el mismo sentido), con lo cual desaparece la posibilidad misma de hallar un significado aceptable por todos, desapareciendo de paso con el no literalismo y los hallazgos históricos, partes esenciales de lo que fundamenta teológica y moralmente el Cristianismo y el Judaísmo, p.e. los Diez Mandamientos. Sin duda, un difícil dilema para unas religiones «de libro», dilema creado por la afirmación del carácter divino de éste, afirmación comprometida en la cual nada ha tenido que ver científico alguno y que traslada a sus autores el peso de la carga de la prueba ante los múltiples errores científicos y contradicciones doctrinales. Un libro que hace tan solo doscientos cincuenta años era la verdad divina revelada, impuesta coercitivamente casi dos milenios, y en cuyo nombre se condenaba e incluso quitaba la vida a los que osaban atenerse a su propia razón o discrepar. Un libro sobre el cual sigue jurándose aun en algunos países como garantía última de verdad a pesar de sus múltiples errores científicos y contradicciones doctrinales, y que hoy, resulta incapaz de sostener su veracidad y coherencia desgarrado ante el dilema planteado por la crítica de la razón, lógica y científica.

Un dilema inexistente cuando se acepta, como para el resto de las obras con carga mítica presentes en todos los pueblos, su carácter de creación humana, de obra de un pueblo como los demás y de su circunstancia geohistórica en busca de sentido y justificación. Una vez aceptada esta tesis, las cosas se simplifican, tanto para la interpretación de lo verificable científicamente - los errores, comprensibles, son hijos del nivel científico de su tiempo-, como para las contradicciones doctrinales, hijas de las distorsiones e invenciones de la tradición oral, de la multiplicidad de autores, de tiempos y de intereses nacionales o de grupo. En esta perspectiva, la Biblia se analiza, no desde la perfección exigible a una obra divina, algo que no cumple en absoluto ni en lo doctrinal ni en lo científico, sino de la realidad de su función religiosa e histórica para la supervivencia de un pueblo en un entorno geohistórico difícil, a la que se sacrifican coherencia y verdad. Así, relatos como el de la muerte de Acán 
tras la toma de Jericó por haberse apropiado algo de la parte de Yavhé, el anatema, no comprometerían la bondad divina, sino que serían interpretadas, justificadamente, como el resultado de la rapacidad de la casta sacerdotal, que no hubiera dudado en implicar a Yavhé para proteger su parte del botín: el oro y la plata. En cualquier caso, algo difícil de aceptar sin renunciar a la creencia, minada en sus mismos fundamentos por la desdivinización del texto en que se basa, que pierde su carácter revelado, al igual que el pueblo judío — con un destino tan diferente de sus sueños plasmados en la Biblia— su carácter de «pueblo elegido».

\section{El diluvio universal: una posible gran inundación en el Antiguo Sumer}

El texto bíblico reúne dos narraciones completas e independientes, entremezcladas, correspondientes a las fuentes J, originada en el reino meridional de Judá, y $\mathrm{P}$, del reino de Judá en época del rey Ezequías, narraciones completas cada una que pueden verse separadas en Friedman (1987).

Tanto este texto como el relativo a Sodoma y Gomorra son diferentes del de la Creación en el sentido de que se refieren a supuestos hechos históricos, pudiendo, por tanto, ser contrastados en cuanto a su historicidad de acuerdo con los métodos de la investigación histórica, y evaluados en sus implicaciones físico-naturales de acuerdo con los conocimientos de las Ciencias de la Tierra. La combinación de ambas vías de investigación, puede suministrar explicaciones plausibles acerca del posible núcleo histórico existente en la leyenda, configurado en lo restante por la tradición oral, en la vía de la Geomitología (Vitaliano, 1973).

De acuerdo con Gén. 7, 2: «De todos los animales limpios has de tomar de siete en siete (...) mas de los animales inmundos <los sometidos a tabú, p.e. el cerdo $>$ de dos en dos»; pero en Gén. 6, 19 se había dicho ya: «Y de todos los animales de toda especie meterás dos en el arca». Un típico doblete contradictorio procedente de la inclusión de las fuentes $\mathbf{J}$ y $\mathrm{P}$ en el texto.

Desde el XIX, se han encontrado muchas tradiciones sobre diluvios universales (Andrée en 1891 había recopilado 85, Vid. Henning, 1950), pero p.e., esta tradición no existe en una civilización tan antigua como Egipto. Además, las diversas tradiciones carecen de sincronía. Así, el diluvio griego de Deucalión — probablemente un tsunami en una zona sísmica, quizá el hundimiento sísmico de la ciudad de Hélice-, es muy posterior al del relato bíblico. Probablemente, grandes inundaciones de carácter regional (en aquellos tiempos la mayoría de la gente no viajaba, y su pequeño mundo era, simplemente, el mundo), un fenómeno ampliamente repartido, constituyen el núcleo histórico de estas leyendas, no una inundación simultánea y universal como la del AT, físicamente imposible.

Algunos detalles como el arca o las aves liberadas por Noé al final del Diluvio, están presentes ya en la epopeya sumeria de Gilgamés, que hace referencia a acontecimientos en torno al 2700 a.C. protagonizados por Utnapishtim en el área sur del moderno Irak. Esta epopeya fue escrita hacia 2000 a.C., cuando el pueblo hebreo ni tan siquiera existía como tal. En realidad, el relato del Diluvio es una inserción en Gilgamés procedente del Poema de Atraharsis, el Noé primigenio, escrito hacia 1650 a.C. (Bottéro, 2003). El paralelismo en lo cronológico del relato hebreo con la lista de los reyes sumerios sugiere también que el relato se tomó de fuentes sumerias, tal y como sugiere la Enciclopedia Británica. Este origen es compatible con un posible núcleo histórico: una gran inundación regional en el bajo Eúfrates, en Sumer (Ayala-Carcedo, 2001 y 2002). De hecho, las formaciones aluviales del río presentan diversas capas de lodo que son la huella de pasadas inundaciones. En definitiva, la cultura hebrea, como casi todas, no habría podido sustraerse a la influencia 


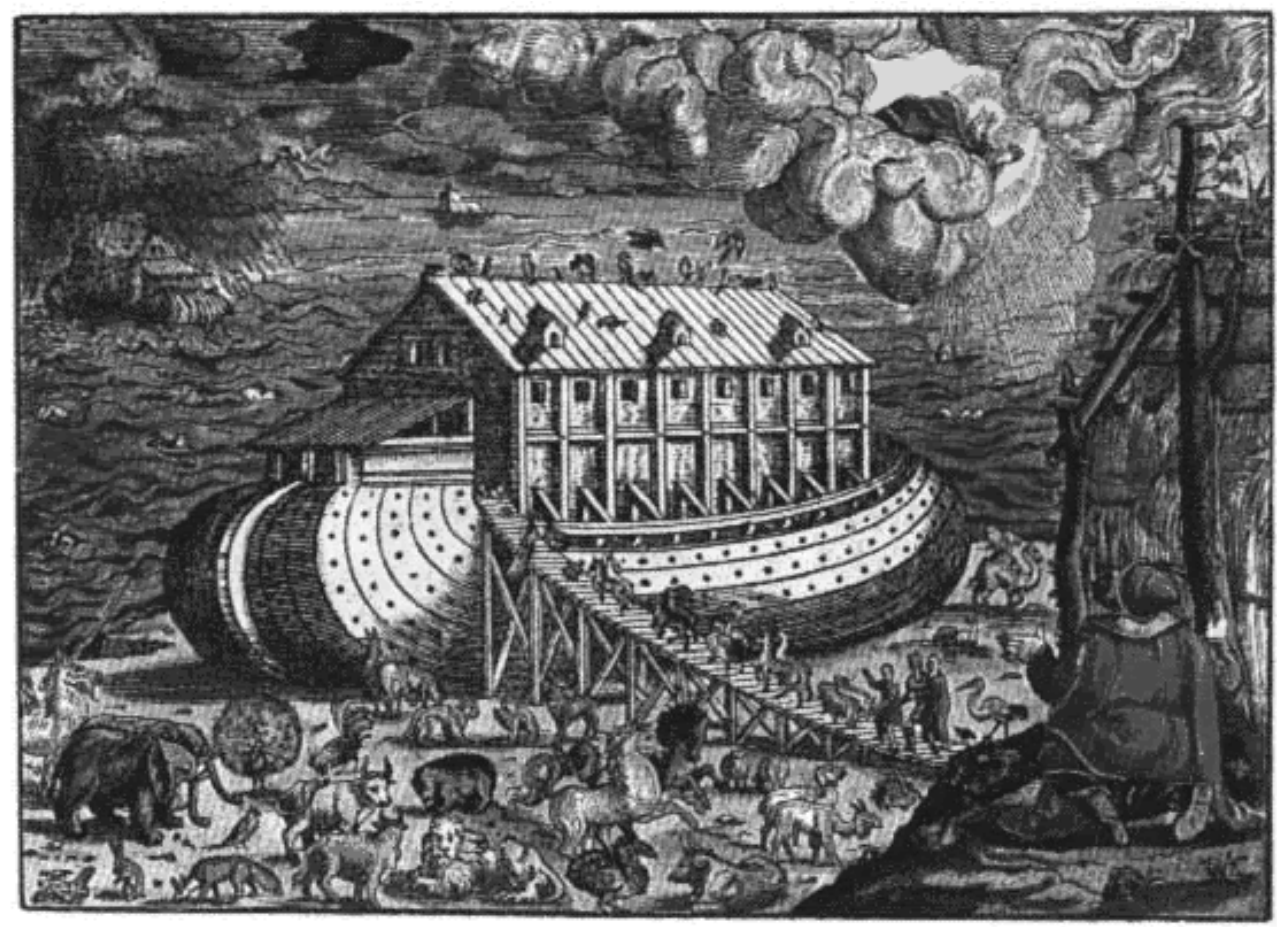

Figura 7. El Arca de Noé de acuerdo con una ilustración alemana del siglo XVI, cargando los animales, una operación logística de tal complejidad que ni tan siquiera hoy sería posible.

cultural de sociedades mucho más antiguas y poderosas; para autores como Greenberg (2000), especialista en Mitología comparada, la influencia es tan grande que no duda en titular su libro «Como los antiguos escribas inventaron la historia bíblica». Por otra parte, los plagios y préstamos culturales han sido y son la norma en la historia de las sectas y religiones (Vidal, 1995).

Desde la razón científica se han presentado múltiples objeciones contra la veracidad del relato bíblico, muchas de las cuales pueden verse en Isaak (1998) o Ayala-Carcedo (2001 y 2002). Un primer problema es el logístico. De acuerdo con la Biblia, Noé llenó el arca en siete días (Gén. 7, 4) con una pareja al menos de cada especie (Gén. 6, 19). Actualmente, se estima puede haber entre 20 y 100 millones de especies. Una operación logística impensable en nuestros días...más cuando ni tan siquiera se conocen todas las especies. ¿Cómo podrían haberse alimentado durante más de trescientos días todos estos animales? ¿Cómo habrían convivido predadores y presas?

Por otra parte, aunque cayera toda el agua contenida en la atmósfera y se fundiera todo el hielo y la nieve, basta un sencillo cálculo a partir del balance hidrológico mundial, no llegaría ni de lejos para empezar a «Cubrirse todos los montes encumbrados debajo de todo el cielo» (Gén. 7, 19) (Ayala-Carcedo, 2001). Para superar este problema, en la polémica en torno al Diluvismo, Burnett propuso una Tierra plana prediluvial, una idea recuperada por los creacionistas «científicos». 
De acuerdo con $\mathrm{P}$ o $\mathrm{S}$ «Yahvé (...) hizo soplar el viento sobre la tierra, con lo que se fueron disminuyendo las aguas». Pero como se ha comentado, la atmósfera no podía absorber todo ese vapor: cada $\mathrm{m}^{3}$ de agua, tiene una capacidad máxima de contener vapor de agua, la humedad absoluta. Una alternativa es que el agua fuera al «grande abismo de los mares» (Gén. 7,11), algo que ningún registro sismológico ha encontrado y que originó una de las más pintorescas hipótesis generadas en defensa del Diluvismo, la de la Tierra hueca (Sequeiros, 2000), recuperada por cierto por los nazis (Vidal, 1995), paradigma del irracionalismo y la barbarie en el siglo XX. Además, como ha dicho Vitaliano (1973), el agua caída, hubiera vuelto, simplemente... a rellenar el mar, origen último de la inmensa mayor parte del agua evaporada, pero algo que quedaba fuera del horizonte mental de los autores bíblicos ya que, como se dijo, pensaban que el origen de la lluvia diluvial, estaba en el agua que rodeaba la bóveda celeste más allá de las estrellas. En definitiva, tanto el origen del agua necesaria para un diluvio como el bíblico, como su destino tras el mismo, son científicamente inexplicables.

Otro problema se relaciona con las plantas, no recogidas en el arca, lo que hubiera llevado a la extinción de no pocas. Pero no hay evidencia alguna de esa extinción paleontológica universal. Por otra parte, el supuesto Diluvio hubiera producido una indudable huella geológica y paleontológica, una formación sedimentaria universal con abundantes fósiles. Ya Lyell criticó en sus Elementos de Geología, en el capítulo VI, tanto la idea de uno o varios diluvios como la de su depósito, el «diluvium», y ningún geólogo ha encontrado nunca nada parecido. Al contrario, en el Holoceno, los últimos 10.000 años, y en el Pleistoceno (desde hace 1,6 millones), hay multitud de formaciones sedimentarias pero sin sincronía que evoque lo que se deduciría del relato bíblico.

De acuerdo con la fuente $\mathrm{P}$, el arca acabó reposando sobre los montes de Armenia (Gén. 8, 4). A pesar de las múltiples expediciones en busca del arca al monte Ararat, ésta, como era esperable, no ha sido encontrada. Un trozo de madera hallado por Ferdinand Navarra en 1955, fue datado como del año 700 (Science News, 1977). Uno de los últimos «hallazgos»...era en realidad el fondo de un sinclinal con aspecto de casco de barco, interpretado erróneamente como el Arca fosilizada (Fortey, 2000).

Ryan y Pitman (1998) han planteado que el posible núcleo histórico de la leyenda correspondería en realidad a la gran inundación que hace unos 7.500 años produjo la invasión por el Mediterráneo ascendente tras la glaciación, una transgresión que inundó el Mar Negro, un hecho científico comprobado en campañas oceanográficas. Sin embargo, las dataciones de maderas procedentes de asentamientos humanos enterrados bajo el mar, han dado fechas demasiado recientes para ser coherentes con el relato sumerio tomado por la tradición hebrea. Por otra parte, el relato sumerio-bíblico es muy claro en cuanto al origen del Diluvio: la lluvia («las cataratas del cielo»), no la invasión del mar.

Una exposición sobre el Diluvio desde el creacionismo «científico», puede verse en Withcomb \& Morris (1989) o en Sarfati (1998), para cuya crítica se recomienda ver el trabajo de Isaak (1998).

\section{La destrucción de Sodoma y Gomorra: una posible catástrofe geológica en las riberas del Mar Muerto}

Sodoma y Gomorra estaban situadas en la ribera del Jordán, «de regadío por todas partes» (Gén. 13, 10), cerca del Mar Muerto —entonces el Valle de Siddim, Valle de las Selvas-, el área escogida por Lot, sobrino del patriarca hebreo Abraham, que había venido de Egipto con ganado para establecerse. Yahvé decidió comprobar si era tan frecuente la homosexualidad masculina entre sus habitantes como indicaba el clamor que 


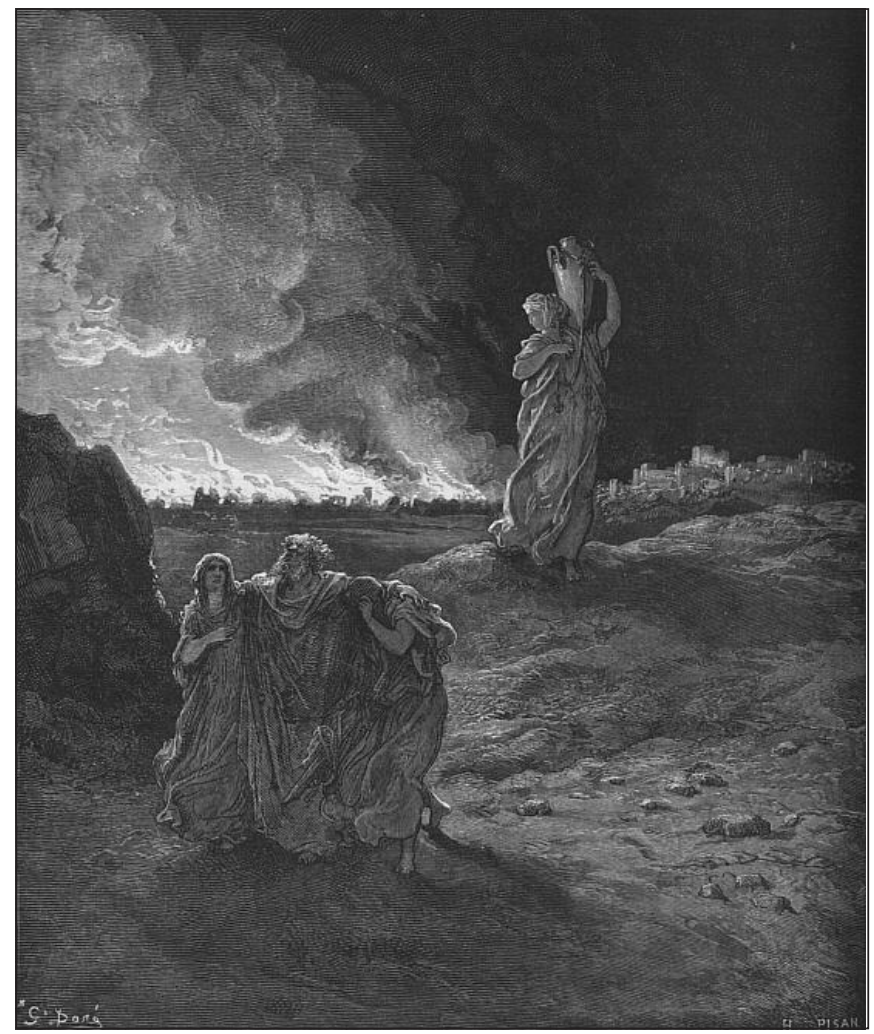

FIGURA 8. Huida de Lot y su familia de Sodoma y Gomorra en llamas según Gustave Doré (1832$1883)$.

había llegado a sus oídos (Gén. 18, 21), enviando para ello dos ángeles que fueron invitados a casa de Lot, en Sodoma; efectivamente, los hombres de la ciudad, tal y como Yahvé había previsto en su infinita sabiduría, desearon «conocer» en el sentido bíblico a los dos ángeles. Lot y su familia pudieron escapar de la cólera de Yahvé cuando «El Señor llovió del cielo sobre Sodoma y Gomorra azufre y fuego» (Gén. 19, 24). Este supuesto hecho es el que está en la base de la condena de la homosexualidad por amplios sectores de las jerarquías eclesiásticas cristianas - no de la mayoría de los creyentes en los países desarrollados-, condena recientemente reafirmada en julio de 2003 por el cardenal Ratzinger.

El relato, confrontado con la realidad histórica, tiene varios anacronismos y fue escrito probablemente ya en el Primer Milenio a.C., guardando estrecho paralelismo con otro relato bíblico, el de Jueces 19, lo que sugiere una fuente común (Greenberg, 2000). En realidad, el texto está configurado por la reunión de las fuentes $\mathrm{J}(19,1-28 ; 30-38)$ y P (19, 29) (Friedman, 1987).

El Valle de Siddim «tenía muchos pozos de betún» (Gén. 14, 10). Por otra parte, el Mar Muerto, es un rift geológico, un valle tectónico creado por procesos distensivos, de apertura de fracturas y fallas, prolongación del rift africano, una zona sísmica cuyo fondo está casi $800 \mathrm{~m}$ bajo el nivel del Mediterráneo, abundando las fuentes termales con azufre. 
Blanckernhorn (1896) sugirió que las ciudades del Mar Muerto se hundieron y fueron cubiertas por dicho mar tras un terremoto. En el siglo I, Estrabón constató, sin embargo, que las murallas de las ciudades todavía existían.

A su vez, Frederick Clapp (1936), sugirió que el betún pudo fluir por una zona de falla durante el terremoto y después ser incendiado por un rayo o fuegos urbanos. De hecho, en el Mar Muerto se observan masas de asfalto flotantes que tienen este origen. Durante el terremoto de julio de 1927 se produjeron fuegos a consecuencia de la ignición de gas natural, metano (Henning, 1950). Graham Harris y Anthony Beardow (1995), han sugerido que la causa de la catástrofe podría haber sido la licuación sísmica alrededor de 1900 a.C., licuación que podría haber desencadenado una extensión lateral, un tipo de deslizamiento en zonas de poca pendiente, bajo las ciudades, localizadas en la Península de Lisan, entre las dos subcuencas del Mar Muerto, produciéndose también incendios.

Wood (1999) ha sugerido que las ruinas de ambas ciudades son las hoy denominadas Bab adh-Dhra (Sodoma) y Numeira (Gomorra), en el SE. del Mar Muerto, hoy en Jordania. Ambas ruinas muestran signos de haber sido destruidas por incendios.

No existe unanimidad, por tanto, acerca de la situación de las ruinas, ya que han sido situadas también en el borde septentrional por una expedición con minisubmarino en 2000 dirigida por Michel Sanders, un experto bíblico.

Parece, pues, que hay suficientes elementos geológicos para abogar por una catástrofe de origen natural - bien distinta de la planteada en el relato bíblico en cuanto a sus causas, sobrenaturales-, que soportaría un núcleo histórico y, por tanto, un carácter legendario más que mítico. Sobre esta posible base natural, los autores bíblicos, conocedores como en el caso del Diluvio del poso dejado en la tradición oral cuando escribieron el relato, unos mil años después, probablemente tejerían una interpretación causal de carácter religioso: el poder divino para el castigo absoluto, la muerte de los impíos que, como Onán, otro condenado, no contribuían al «creced y multiplicaos» del «pueblo elegido».

Aportan solidez a esta aproximación las investigaciones llevadas a cabo recientemente para aclarar otros elementos de la Historia Antigua dotados por la tradición de un supuesto halo sobrenatural. La trama geológica de un elemento cultural de la importancia del Oráculo de Delfos en el templo de Apolo, el más importante de la Antigüedad, en Grecia, acaba de ser confirmada, avalando científicamente lo expuesto por Plinio o Plutarco. El oráculo, está situado en la intersección de dos fallas de gravedad por las que ascendían gases con etileno - hidrocarburo no saturado de olor agradable empleado como anestésico: $\mathrm{CH}_{2}=\mathrm{CH}_{2}$-, procedentes de unas calizas bituminosas, gases que provocan un estado similar al trance en el que según los contemporáneos que lo presenciaron, caían las sacerdotisas pitonisas (Hale et al., 2003). Esta vía de investigación doblemente apoyada en la Historia y las Ciencias Naturales (en este caso la Etnobotánica), se ha mostrado también fértil en el descubrimiento del probable núcleo verdadero de los Misterios de Eleusis, otro elemento cultural central de la Antigüedad que dejaba profunda huella en los que lo vivían. El misterio parece ser que se basaba en la ingestión por los futuros iniciados, controlada por los sacerdotes, de la esencia del cornezuelo, uno de los múltiples ejemplos de utilización místico-religiosa de las drogas (Gordon et al., 1978).

Las catástrofes geológicas, por su violencia y espectacularidad, incomprensibles hasta hace muy poco, capaces de impresionar a muchas generaciones y entrar en la tradición oral, serían así elemento idóneo para mostrar la cara amarga del supuesto poder divino, el castigo para los que no aceptan la Escatología ${ }^{7}$ y el código moral sacerdotal,

7 Escatología: conjunto de creencias y doctrinas sobre el destino final del hombre y el universo. 


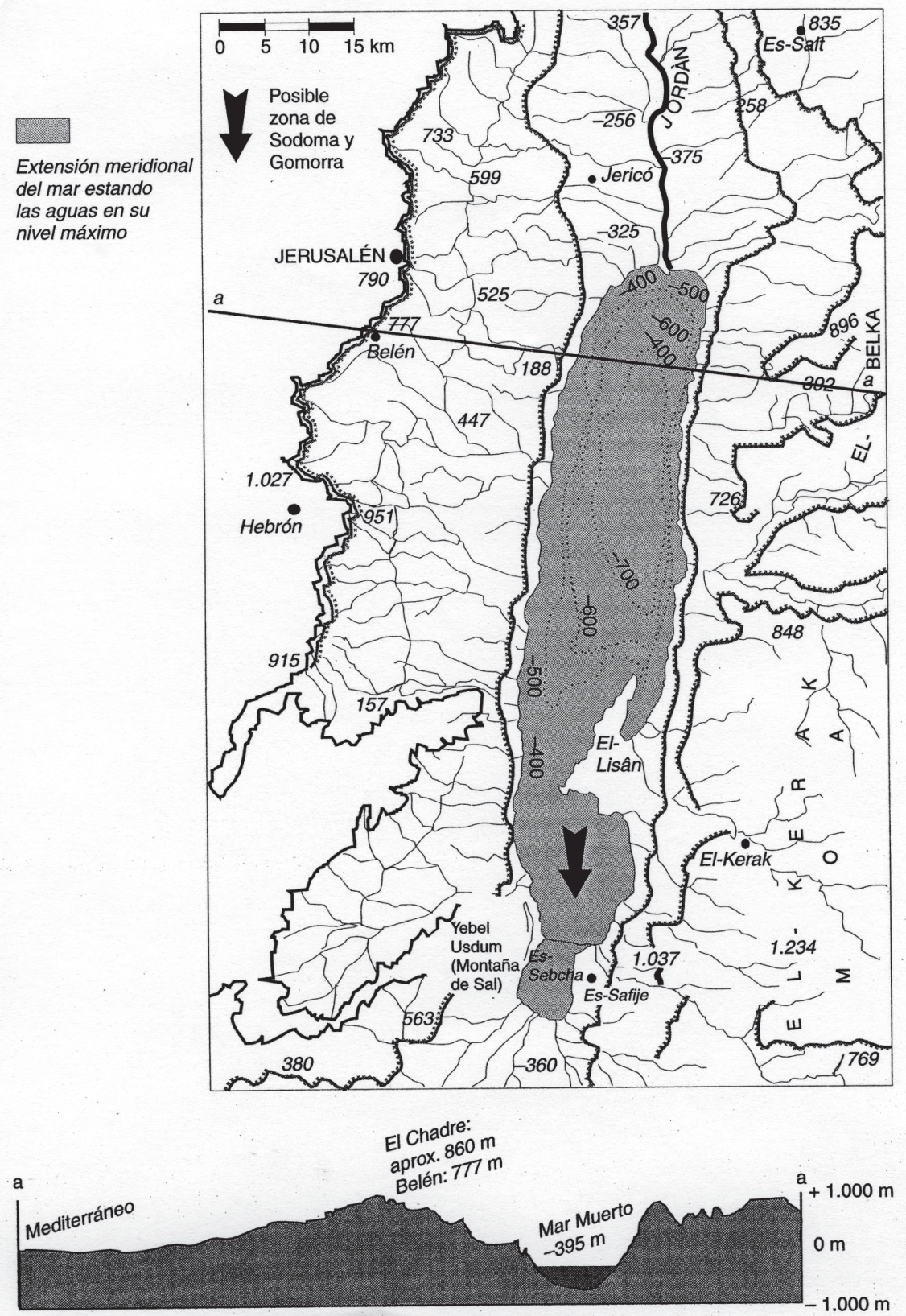

FIGURA 9. Una de las posibles localizaciones de las antiguas ciudades de Sodoma y Gomorra, posiblemente destruidas hacia 2000 a.C. a consecuencia de la licuación del suelo en un terremoto acompañado de incendios producidos por la ignición de gas natural liberado y el asfalto, abundantes en la zona (Henning, 1950, mod. por Ayala-Carcedo, 2002). 
opuesto a la amable, el milagro al servicio de los «elegidos» o de la propagación de la fe. Esta misma interpretación de instrumento de amenaza, de advertencia permanente a los que se desvíen, reiterada en los Evangelios en boca de Jesús (Vid. p.e. Mateo 10, 15 ó $11,24)$, es la que sugiere la utilización recurrente del relato, en este caso el del Diluvio, como amenaza a los impíos en el libro sagrado musulmán, El Corán, que lo toma en préstamo de la tradición judía al igual que ésta lo tomó de la sumeria, cada una con su propia interpretación. No acaba ahí el paso de mano en mano del mito: los nazis —cuyas siniestras SS se inspirarían a nivel organizativo en la Compañía de Jesús, por la que el excatólico Himmler (Vidal, 1995), como antes Lenin, creador del otro gran totalitarismo moderno, sentía gran admiración-, lo tomarían, en combinación con el mito o leyenda de la Atlántida transmitido por Platón, como elemento fundante de la supuesta superioridad racial aria, del nuevo «pueblo elegido», el «herrenvolk», el pueblo de los señores; un pueblo supuestamente salvado del Diluvio Universal en las altas montañas del Tibet tras la destrucción de la Atlántida (Ravenscroft, 1991) y al que esperaba una apoteosis triunfal en forma de un Reich de mil años de la mano del mesías redentor de la raza aria, Adolf Hítler.

Las derivaciones del fundamentalismo religioso o parareligioso, a menudo al servicio de nacionalismos exaltados o de la razón de Estado, distan a menudo de ser inocuas, y en su nombre se han realizado algunos de los más horrendos crímenes contra la Humanidad, que van desde los supuestos genocidios que la Biblia describe — de Egipto, con todos sus primogénitos muertos a manos de Yahvé, a la inventada conquista de Canaán-, al Holocausto nazi del siglo XX (los nazis crearon su propia Iglesia, pagana, la Gottgläubige, el Movimiento de la Fe, Vid. Grunberger, 1971) o el practicado por la Santa Inquisición en los siglos XV-XVIII contra las supuestas brujas en Europa, que costó la vida al menos a unas 50.000 personas torturadas salvajemente y quemadas o ahorcadas (Behringer, 1997). Es obvio, por otra parte, que el actual fundamentalismo cristiano norteamericano, ligado a los sectores más conservadores del Partido Republicano y al propio presidente Bush Jr. (James, 2003), con su idea mesiánica del «nuevo pueblo elegido» y el enorme poder de EE.UU., está detrás, ideológica y en cierta medida políticamente, del intervensionismo imperial que caracteriza actualmente la política exterior norteamericana. Intervencionismo fruto de los bárbaros atentados del 11 de septiembre (Herencia Cristiana, 2003) obra de otro fundamentalismo, el islámico. Intervencionismo en buena medida al margen de la legalidad internacional de Naciones Unidas, y con beneficiarios perfectamente identificados: los oligopolios petroleros, el complejo militar-industrial norteamericano y el Estado de Israel. La desmitificación de creencias fruto inevitable del pasado precientífico de la Humanidad, muestra claramente que no hay «pueblos elegidos» investidos por divinidad alguna de supuestas misiones redentoras o trascendentes, que la Humanidad es una en lo biológico y que en esta era de globalización la única salida salvadora pasa por el respeto a los derechos humanos, la tolerancia y el mestizaje cultural. La dinámica ideológica de los fundamentalismos, ayunos todos de racionalidad científica, expresiones del irracionalismo, se realimenta entre unos y otros sin más salida que el choque de culturas que puede acabar presidiendo el nuevo siglo XXI. Por tanto, el fortalecimiento de la racionalidad y su crítica a los endebles postulados que soportan los fundamentalismos de todo tipo, así como la estricta separación de religión y política, base del Estado ilustrado que ha hecho de Occidente el abanderado de los derechos humanos y el progreso científico-técnico e incorporada afortunadamente en el proyecto de Constitución de la UE, son necesarios y obligados para evitar el choque de culturas cuyos prolegómenos, envueltos en ropajes patrióticos pero en realidad al servicio de intereses rapaces y egoístas como los expuestos, estamos presenciando. 


\section{La Biblia y la historia de las Ciencias Geológicas: un desencuentro inevitable}

Durante casi 1.500 años, el cristianismo — la nueva religión de raíces hebreas — no fue cuestionado en Europa. Las principales razones para ello estribaban en la ausencia de explicaciones alternativas a diversas creencias dada la debilidad de las observaciones y los conocimientos científicos; también y no menos, en el enorme poder económico y sociopolítico de la Iglesia Romana, que confería legitimidad divina a las monarquías reinantes, poder que como sucede hoy con el Islamismo, impregnaba toda la vida del creyente. Pero cuando el Renacimiento, surgido en el siglo XV en las Repúblicas italianas y el XVI en el resto de Europa, cambió el leitmotiv de sociedades e individuos de lo divino a lo humano; cuando la Reforma y el libre examen de los textos bíblicos conquistaron media Europa y la Ciencia moderna emergió con fuerza en el XVI, los relatos bíblicos, fruto de una sociedad precientífica, comenzaron, inevitablemente, a ser cuestionados.

Debe tenerse presente que en la época en que se hizo la compilación bíblica la escritura era patrimonio de una reducidísima minoría, poco más que la casta sacerdotal, y que así sería en los países cristianos — no entre los judíos, devenido pueblo culto de lectores asiduos de la Biblia y el Talmud tras la Diáspora_, hasta la aparición de la imprenta y la difusión de los impresos en los siglos XV-XVI. Una de las razones estribaba en lo costoso de los textos escritos, fruto de amanuenses, y en lo caro de los soportes materiales de la escritura como el pergamino (Ayala-Carcedo, 2000). Probablemente, los compiladores bíblicos sacerdotales nunca pensarían que la mezcla de textos y tradiciones contradictorias o los plagios tomados de otras culturas llegarían a ser examinados por gentes ajenas a la propia casta, entonces analfabetas. Pero gracias al progreso técnico - la imprenta y el papel y el enorme abaratamiento de los escritos que trajeron-, por primera vez, más de veinte siglos después, muchas personas accedían a un conocimiento directo de los textos bíblicos y podían además compararlos con los coetáneos procedentes de otras culturas.

Para los cristianos, la Biblia era la palabra de Dios, una materia de fe, una verdad absoluta sujeta a criterios de autoridad que inevitablemente entraría en conflicto con la razón científica entonces emergente a caballo del humanismo renacentista, basada en la observación, las pruebas, la duda metódica, la actitud crítica y la negación de cualquier criterio de autoridad. Si la Biblia decía «Y paráronse el sol y la luna hasta que el pueblo del Señor se hubo vengado de sus enemigos» (Josué 10, 13), era porque el sol se movía; por tanto, Copérnico, Galileo y su heliocentrismo, sin prueba científica alguna que les valiera, estaban en el error y la herejía. Pero la ruptura de la Iglesia Romana durante la Reforma en el XVI y el ascenso del comercio internacional y más tarde el industrialismo, eran favorables al desarrollo de la Ciencia, necesario para la navegación, la minería o metalurgia. Sin embargo, ciencias como la Astronomía, la Geología, la Biología o la Geografía Física, vieron retrasado su desarrollo debido a los condicionamientos que imponían las creencias en mitos bíblicos como la Creación o el supuesto Diluvio Universal.

Para la Geología, los problemas vinieron con los fósiles y la magnitud del tiempo geológico (Haber, 1959; Toulmin \& Goodfield, 1982; Gould, 1987; Lewis \& Knell, 2001). El primer problema era la cortedad de la Historia de la Tierra que se deducía del relato hebreo, un aspecto en el que la Biblia es notablemente inferior a religiones como el brahmanismo o la maya, con amplias cronologías cosmológicas (Tokarev, 1979).

De acuerdo con Eusebio de Cesarea ( $c a .303$ ), la edad del mundo acorde con la Biblia, era de 6.000 años, similar a la que calcularía en 1658 el arzobispo James Ussher, primado de Irlanda: el mundo había sido creado el 23 de octubre del 4004 a.C. (Faul \& Faul, 1983; Barr, 1985); el Diluvio, de acuerdo con diferentes versiones de la Biblia, habría ocurrido 


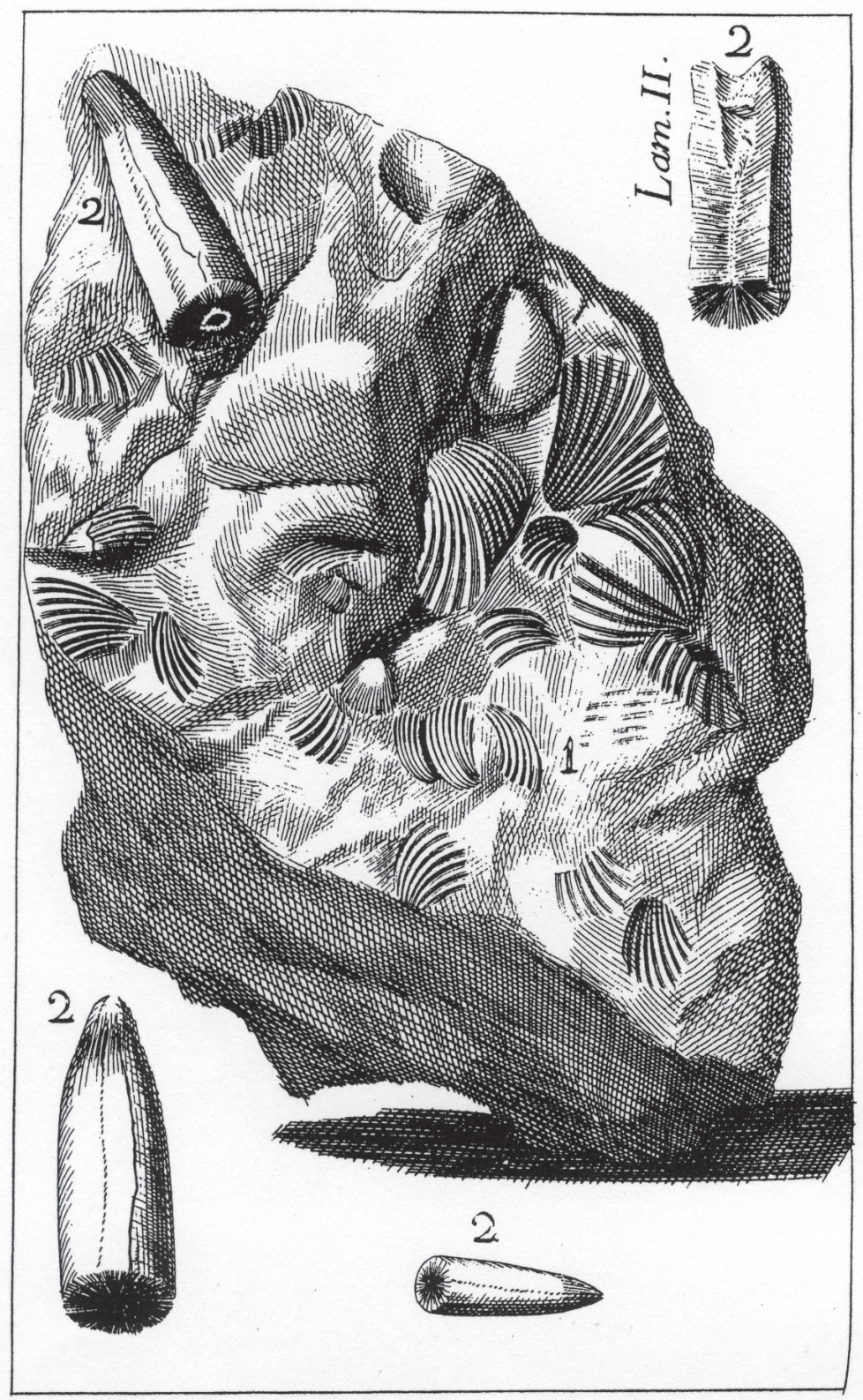

FIGURA 10. Los fósiles, generalizados en todo el mundo, supusieron al principio la supuesta confirmación del Diluvio Universal; después, un reto que cuestionaba el relato bíblico por la evidencia de extinciones incompatibles con el texto del Génesis, por lo que se cuestionó su origen orgánico por el jesuita Athanasius Kircher (1602-1680) en el siglo XVI, en el contexto de Trento. Fósiles marinos descritos por Torrubia (1698-1761), diluvista pero defensor del origen orgánico, en su Aparato para la Historia Natural española, de 1754. 
entre el 3387 y el 2582 a.C., así que la tierra antediluviana solo tenía unos 1.000 años. Para los judíos, de acuerdo con su sistema de contar el tiempo, el año 1067 de la era cristiana p.e., era «el año 4827 de la Creación» según el judío de Arévalo José ibn Zaddic (en Martínez Díez, 1999). Estas cifras eran abiertamente insuficientes p.e. para dar cuenta del papel de los procesos erosivos como productores, junto a los tectónicos, del relieve terrestre, de articular en suma una explicación racional empíricamente fundada a la realidad observada ya al menos desde Al Biruni (973-ca. 1050).

Generalmente se hace énfasis en el descubrimiento geográfico, espacial, del mundo, pero para varias ciencias como las geológicas o las biológicas, el descubrimiento del tiempo, en la afortunada expresión de Toulmin \& Goodfield (1982), de la dimensión temporal del mundo, fue tan importante como el primero.

El conde De Buffon (1707-1788), en su Époques de la Nature de 1778, tras realizar experimentos de calentamiento-enfriamiento con esferas, había estimado la edad de la Tierra en la entonces increíble cantidad de 74.832 años, cifra que la Facultad de Teología de la Universidad de la Sorbona se apresuró a condenar por herética; Buffon, como en el siglo anterior había tenido que hacer Galileo (1563-1642), tuvo que desdecirse ante el poder inquisitorial en que la Iglesia se apoyaba aún en los años previos a la Revolución Francesa de 1789. Buffon, consciente de la importancia clave del tiempo en los procesos naturales, llamó a éste «el obrero de la Naturaleza». Dada la imposibilidad de acuerdo entre razón y fe, las controversias acabarían resolviéndose con el total abandono de las cronologías bíblicas en la Ciencia. El problema de una cronología exacta, no se resolvería sin embargo satisfactoriamente hasta el siglo XX con la datación radiactiva.

El Diluvio bíblico suponía también importantes obstáculos para el desarrollo de la Geomorfología, la Estratigrafía y la Paleontología. Isidoro de Sevilla (ca. 570-636) en sus Etimologías (ca. 630), había dicho que los fósiles eran restos orgánicos del Diluvio. Científicos chinos y musulmanes creían también en su origen orgánico, al igual que Leonardo da Vinci (1452-1519), Steno (1638-1686) y Hooke (1635-1703); Leonardo, el primer europeo en señalar la continuidad entre estratos a uno y otro lado de los valles y, por tanto, su origen erosivo, cuestionaba su origen diluvial. La hipótesis diluvial sobre los fósiles era aceptada por Cardano (1501-1576) y Leibniz (1646-1716) en su Protogea. En España, el P. Torrubia (1698-1761), valioso observador, era diluvista, mientras que Bowles (1705-1780) y Cavanilles (1745-1804), creían que los fósiles eran producto de oscilaciones periódicas del mar (Sequeiros, 2002). Antonio de Ulloa (1716-1795) halló fósiles en Talcahuano (Chile), declarando que eran la prueba de la universalidad del Diluvio bíblico (Capel, 1985). El suizo Scheuchzer (1672-1733), otro diluvista, pensó incluso haber hallado los restos de un hombre pecador ahogado en el Diluvio, al que denominó Homo diluvii testis, en realidad el fósil de una salamandra gigante.

La hipótesis diluvial sobre los fósiles, encerraba un importante problema para la ortodoxia bíblica, problema que afloró en cuanto se comprobó que los fósiles correspondían a especies extintas, ya que Yahvé había ordenado a Noé salvar a «todos los animales de toda especie» (Gén. 6, 19); si la Biblia no citaba extinción alguna antes, durante y tras el Diluvio, ¿Cómo era posible que hubiera especies extintas? ¿Para qué entonces el supuesto acto salvador de Noé ordenado por Yahvé? Coherentemente, el jesuita Kircher (16021680), en el contexto de la Contrarreforma y el Concilio de Trento (1545-1563), declaró que los fósiles no eran restos orgánicos, sino piedras, lapides figurati producto del azar. Otro problema para la hipótesis diluvial, vino cuando Vallisnieri (1661-1730), en 1721, al descubrir fósiles en varias capas diferentes, dijo que eran necesarios varios diluvios y no uno solo para explicarlo. Así que Réaumur (1683-1757), abandonó definitivamente la hipótesis diluvial en su estudio sobre los fósiles de Turenne (Francia). 


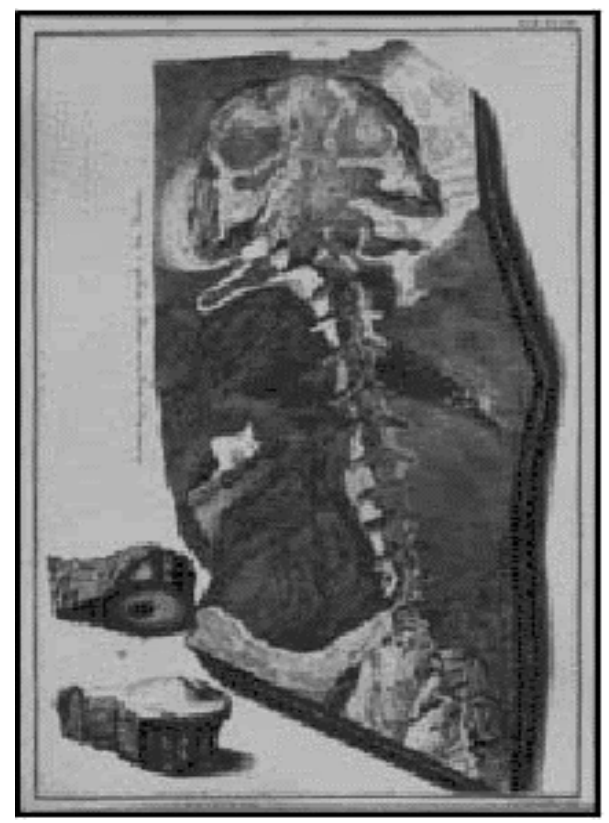

Figura 11. En este fósil, el diluvista Scheuchzer (1672-1733) creyó ver en 1726 los restos de un hombre pecador ahogado en el Diluvio Universal, por lo que fue bautizado como Homo diluvii testis. Cuvier probó en 1812 que, en realidad, se trata del fósil de una salamandra gigante, miocena, varios millones de años anterior a los homínidos. Fósil original en el Museo Tylers en Harlem (Holanda).

Estos debates se vieron acompañados, y enturbiados, por una polémica extracientífica entre providencialistas optimistas como Leibniz, Linneo (1707-1778), o Woodward (16651728) — que creían que la Naturaleza opera según un plan divino de progreso—, providencialistas pesimistas como el diluvialista Burnett (1636-1715) — que pensaba que la Naturaleza se degrada continuamente-, o librepensadores como Voltaire (1694-1778), que pensaban que la omnipresencia del mal en el mundo, realzada a raíz del reciente terremoto de Lisboa de 1755 que había matado a 24.000 inocentes, cuestiona el providencialismo. Descartes (1596-1650), padre del racionalismo, para evitar problemas con la Iglesia católica, declararía que Dios hizo una vez las reglas de la Naturaleza, pero que ésta opera autónomamente con ese impulso inicial; una posición antiprovidencialista y sorprendentemente moderna, condenada en su época por la Iglesia católica, y adoptada en definitiva por la Iglesia en la actualidad. Cosas veredes.

William Smith (1769-1839) y Alexandre Brongniart (1770-1847), acabarían mostrando el significado bioestratigráfico de los fósiles, una noción clave para el establecimiento de la cronoestratigrafía y el desarrollo de las bases geológicas de la minería hullera, uno de los pilares de la Primera Revolución Industrial (1765-1885).

Cuando los españoles y portugueses encontraron que América era un continente aislado y que había animales en él, diferentes de los de Eurasia, apareció un nuevo problema para el diluvismo, ya que Noé había desembarcado su carga viva en la isla-mundo, el Viejo 


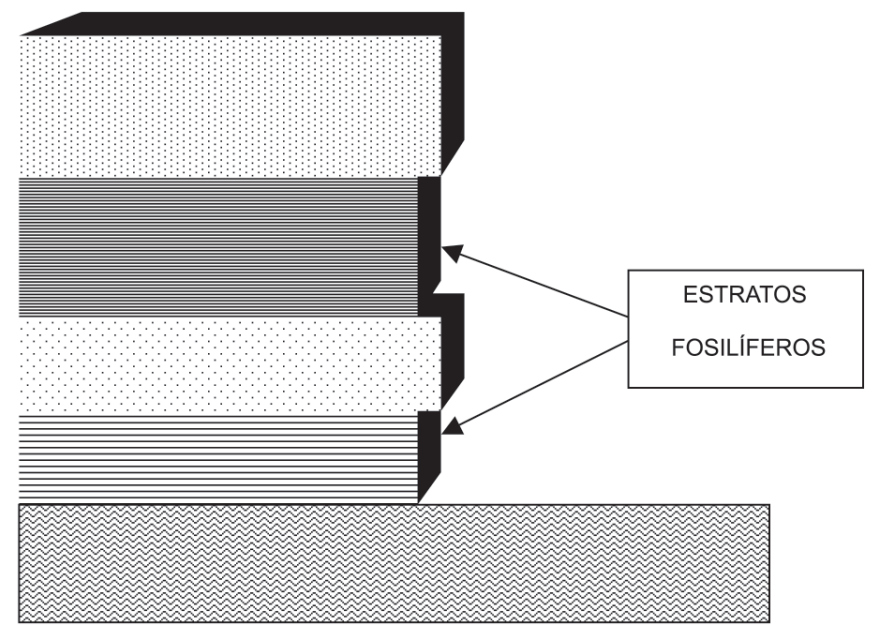

FiguRA 12. Un sencillo corte geológico como éste, supone un cuestionamiento en profundidad del relato bíblico del supuesto Diluvio Universal en la medida en que existan hiatos temporales entre estratos mayores de un año (aproximadamente la duración del Diluvio bíblico) y haya extinciones entre los fósiles de ambos horizontes.

Continente. La presencia de seres humanos en América, incompatible también con el diluvismo, originó, para salvar la ortodoxia bíblica, la pintoresca teoría de los preadamitas, humanos anteriores a Adán que al no estar afectados por el supuesto «pecado original» adánico, no habrían sufrido el castigo divino. Indirectamente, fue la ocasión para que Acosta (1539-1600), autor de la Historia natural y moral de las Indias en 1590, propusiera al observar la complementariedad de sus costas, que América y África habían estado unidas antes del Diluvio, que las habría separado. Una hipótesis ingeniosa que después recuperarían Humboldt y Wegener, pero incompatible con el hecho de que los animales y plantas a ambos lados del océano pertenecían a especies diferentes, algo que sólo la moderna Teoría de la Tectónica de Placas ha sido capaz de explicar en el siglo XX.

El Diluvismo, sin embargo, tenía un aspecto positivo para el progreso científico como ha señalado Capel (1985), ya que aceptaba que la Tierra tenía una «historia», que había cambiado; eso sí, una sola vez y dentro de las tesis bíblicas. En ese sentido, el Diluvismo está de alguna manera, aunque no explícita, tras el Neptunismo de Benoît de Mallet (16651728), Abraham Werner (1750-1817) o John Walker (1731-1803), una teoría que defendía el origen acuoso de todas las formaciones geológicas — granito y basalto incluido_-, en un océano universal primigenio, la Panthalasa. La teoría entró en crisis tras mostrar el escocés James Hutton el origen ígneo del granito; sin embargo, por su énfasis estratigráfico, permitió algún progreso en este campo. El Neptunismo, vencido científicamente de forma definitiva por la magna síntesis de Lyell en sus Principles of Geology de 1830-33, no superó en general 1850, pero en EE.UU., a través de los geólogos yankees de raíz puritana y de Agassiz, discípulo de Cuvier, tuvo más vigencia (Faul \& Faul, 1983); algo que ayuda a explicar la fuerza del fundamentalismo cristiano diluvista. Al igual que otros grandes científicos de su época como Darwin, Lyell sería objeto de la censura eclesiástica, teniendo que asegurar al obispo de Londres en 1831 para enseñar en el King's College que sus 
enseñanzas no eran contrarias a la Biblia (Virgili, 2003). En España, a través de los ingenieros de minas que habían estudiado en Freiberg, cuna del Neptunismo werneriano, ha mantenido algún eco anacrónico de carácter semántico hasta mediados del siglo XX en el uso de términos como «estrato cristalino»o «diluvial» en los mapas geológicos oficiales.

Cuvier (1769-1832), fundador de la Anatomía Comparada, representó el último gran intento de conciliar parcialmente los puntos de vista bíblicos con el nuevo conocimiento sobre los fósiles a través de su obra de 1812 Discours sur les Revolutions du Globe en la que propone el fijismo catastrofista: creación divina separada de las especies tras catástrofes universales conducentes a la extinción en masa. Cuvier basó su teoría en la observación de Geoffroy Saint-Hilaire (1772-1884) durante la expedición napoleónica a Egipto sobre la similitud de los animales momificados en las tumbas varios miles de años atrás con los actuales; para Saint-Hilaire, un lamarckiano, 3.000 años eran poco tiempo para dar significación científica al hecho. El creacionismo catastrofista de Cuvier -incoherente en todo caso con la Biblia - gozó de un breve esplendor en la Europa postnapoleónica y retrógrada de la Santa Alianza, pero cayó rápidamente en el descrédito; hoy es un autor citado a menudo por los autodenominados creacionistas «científicos».

La primera teoría de la evolución fue la de Lamarck (1744-1829), discípulo de Bufón. Pensaba, correctamente, que los seres vivos evolucionan, y, erróneamente, que lo hacen a través de la transmisión a su descendencia de los caracteres adquiridos durante su vida positivos para la supervivencia.

Las evidencias paleontológicas de que las formaciones más antiguas contienen fósiles menos evolucionados que las modernas, prueba por otra parte de extinciones en masa, fueron uno de los pilares en los que Darwin, deudor de la síntesis geológica de Lyell, apoyó su Origin of Species de 1859, el libro que enterró definitivamente el creacionismo y el providencialismo en el campo científico (Vid. p.e. Evolution Web Sites, 2002).

La polémica continúa todavía en EE.UU. por parte de los autodenominados creacionistas «científicos», metidos en un callejón sin salida: el cuestionamiento de la Ciencia. La Iglesia católica, más pragmática y menos dependiente de la cultura de lectura bíblica que las Iglesias reformadas, ha acabado por aceptar la evolución con un sentido teísta no muy alejado del propugnado erróneamente por el jesuita Teilhard de Chardin («Una integración intelectual, en la cual el cosmos en evolución revela la presencia del Logos Divino, tanto en los procesos de la cosmogénesis como en los de la antropogénesis» según Mons. Józef Zycinski, Arzobispo de Lublin en 1998), carente de fundamento científico (Vid. p.e. Ayala, 1994 o Arsuaga, 2001). Tras varias centurias de sistemática y diligente persecución, la Iglesia católica, ha levantado al fin la condena a Galileo por su heliocentrismo. En este caso, la verdad ha acabado imponiéndose. Eppur si muove.

\section{Conclusiones: la Cosmología y Geología bíblicas, obra de un pueblo precientífico}

Desde la razón científico-natural, cabe concluir en lo siguiente.

En cuanto al relato bíblico de la Creación, no verificable científicamente en cuanto a su historicidad, pero si en cuanto a sus tesis, los dos tercios de éstas al menos son erróneas o falsas. Así, p.e.: la creación del día y la noche antes de crear el sol; la creación de herbáceas y plantas antes de crear el sol, necesario para la fotosíntesis; la existencia de agua por encima de la bóveda celeste; la creación de estrellas y planetas tras la del firmamento; la creación separada de cada especie; la ausencia de extinciones como parte necesaria de la generación de la actual biodiversidad etc. Todo el relato, con préstamos míticos de otras culturas, es, además, rehén de una concepción claramente geocéntrica y, por tanto, errónea, sobre el Sistema solar y el Universo. 
La narración bíblica del supuesto Diluvio Universal es incongruente con la completa ausencia de una mínima huella universal estratigráfica, paleontológica o antropológica del mismo, falta de huellas que va acompañada de múltiples evidencias en contra de este supuesto evento, lo que lleva a concluir en la inexistencia de una catástrofe de esta naturaleza que se extendiera a todo el mundo, en la ausencia de un carácter universal. No existe ni hay elemento alguno que permita suponer que haya existido un mecanismo que posibilitara la precipitación de una cantidad de agua tal que produjera un evento como el bíblico en su época. Ni tan siquiera en la actualidad hay posibilidades de la organización de una logística que permitiera preservar en el Arca, obviamente incapaz por sus limitadas dimensiones, todas las especies vivas, desconocidas aun en su mayor parte. Dado el claro origen sumerio del relato, cabe suponer que exista un núcleo histórico del relato en una gran inundación regional en el antiguo Sumer, en el bajo Eúfrates, en el Tercer Milenio a.C.

El relato bíblico de la destrucción de Sodoma y Gomorra, situadas ambas en el rift del Mar Muerto, podría tener un núcleo histórico en la licuación sísmica del suelo bajo las ciudades acompañada de la ignición de gas natural liberado en el terremoto.

Los posibles núcleos históricos de los relatos del Diluvio y Sodoma y Gomorra, sugieren una causalidad natural actuante en el Tercer y Segundo Milenio a. C. respectivamente, similar a la actual, sobre la cual se tejería muy posteriormente una interpretación en clave religiosa transmitida oralmente hasta su escritura en el Primer Milenio a.C.

La presencia del relato bíblico en la Historia de la Geología se produjo primeramente en torno a la discusión del paradigma Diluvista, polémica en la cual se construyeron los cimientos de la moderna Ciencia Geológica. Este paradigma aportaba una limitada idea geodinámica que no impidió completamente el estudio de los procesos y está en alguna medida tras el surgimiento del paradigma Neptunista, etapa primitiva de la Estratigrafía. Junto a este elemento muy limitadamente progresivo, las implicaciones de la ausencia de extinciones impedían el progreso paleontológico, y la extrema cortedad del tiempo geológico, impedía explicar el papel de los procesos geodinámicos externos en la conformación del relieve y la propia evolución de las especies. La progresiva carencia de poder explicativo del paradigma bíblico-geológico, llevaría a su abandono en el siglo XVIII y al triunfo de una parte de las síntesis huttoniana y lyelliana, y de otra al surgimiento del evolucionismo científico, el darwinismo.

Debe señalarse que antes del «descubrimiento del tiempo», en ausencia de una concepción adecuada de la enormidad de los tiempos cosmológico y geológico, sólo disponible en el siglo XIX para el geológico y del XX para el cosmológico, el relato bíblico era una explicación relativamente verosímil para una gran parte de la población en torno a problemas como el cosmológico, el geológico o el de la biodiversidad. Esta realidad y el enorme poder eclesial, explican el éxito del relato bíblico durante muchos siglos.

Junto a los múltiples errores científico-naturales, los textos bíblicos antiguos y neotestamentarios, por otra parte, han sido sometidos a crítica histórico-científica encontrando múltiples contradicciones, contradicciones que vienen de la presencia de diversas tradiciones, hayan sido refundidas en un solo texto como en el Antiguo Testamento, o no, como en el Nuevo. Por otra parte, la historicidad de no pocos hechos clave, del Exodo a la conquista de Canaán, personajes como Moisés o José, o la propia originalidad del cristianismo tras los manuscritos del Mar Muerto que prueban la influencia esenia, es ampliamente cuestionada por historiadores y arqueólogos.

Actualmente, desde el punto de vista de la razón científico-natural e histórica, el relato bíblico, con múltiples contradicciones en lo doctrinal por otra parte, explicables antropológicamente, es sólo comprensible como obra de un pueblo precientífico en sus coordenadas 
geohistóricas y temporales, de forma similar a las tradiciones míticas y legendarias de otros pueblos. Esta tesis elimina el profundo dilema que la crítica tanto de la razón lógica como de la científica, suponen a nivel doctrinal y científico para el texto bíblico. Hoy, la admisión de la veracidad de los relatos bíblicos analizados en sus aspectos científicos, es comprensible como acto de fe, pero no desde la razón científica, razón desde la cual no puede seguir sosteniéndose la idea apologética de que la Biblia tenía razón.

\section{Agradecimientos}

El autor desea agradecer las informaciones, sugerencias y comentarios críticos (en algún caso desde el disenso) a la primera versión inglesa de este texto, bastante más reducida, de David Oldroyd, de la Universidad de New South Wales (Australia), del profesor José Manuel Ontañón, y Octavio Puche, de la Universidad Politécnica de Madrid, el primero y el último, miembros de INHIGEO.

El contenido del artículo es de la exclusiva responsabilidad del autor.

\section{Bibliografía}

ANGUITA, F. (1988): Origen e historia de la Tierra. Madrid, Ed. Rueda.

ARNHEIM, M. (1984): Is Christianity True? Duckworth, London. Trad. en Barcelona, Crítica, ¿Es verdadero el Cristianismo?, 236 pp.

ARSUAGA, J. L. (2001): El enigma de la esfinge. Barcelona, Plaza \& Janés, 415 pp.

AYALA, F. J. (1994): La naturaleza inacabada. Ensayos en torno a la evolución. Barcelona, Salvat, $270 \mathrm{pp}$.

AYALA-CARCEDO, F. J. (2002): Catástrofes Naturales, mitos, religiones e historia. En AyalaCarcedo y Olcina eds., Riesgos Naturales, Barcelona, Ariel, págs. 103-124. Ligeramente modificado en la Revista de Aficionado a la Meteorología: http://www.meteored.com/ram, № 10 y 11 de 2003.

AYALA-CARCEDO, F. J. (2001): Noah's Flood and Science: A Short Review and Analysis. INHIGEO Newsletter. Sidney, International Commission on the History of Geological Sciences, UNESCO, 33, 27-30.

AYALA-CARCEDO, F. J. (2000): La última Revolución de la Información. El Mundo, Nueva Economía, Madrid, 26 de diciembre.

BARR, J. (1985): Why the World was Created in 4004 B.C.: Archbishop Ussher and Biblical Chronology. Bulletin of the John Rylands University Library 67, págs. 575-608.

BLANKENHORN, M. (1896): Entschung und Geschichte des Toten Meeres. Zeitschirft des Deutschen Palästina-Vereins, XIX, 51.

BEHRINGER, W. (1997): Witchcraft persecutions in Bavaria. Cambridge University Press.

BOTTÉRO, J. (2003): La plus vieux récit du Délage. En La Biblié, Tailandier, Paris, 227-248.

BUNGE, M. (1985): Seudociencia e ideología. Madrid, Alianza Universidad, 252 pp.

CAPEL, H. (1985): La física sagrada. Barcelona, El Serbal.

CARNICER, R. (1978): Gracia y desgracias de Castilla la Vieja. Barcelona, Plaza \& Janés, 509 pp.

COOGAN, M. D. (1998): The Oxford History of Biblical World. Oxford University Press.

CREATION SCIENCE AND EARTH HISTORY (2002): http://www.geocities.com/earthhistory/

DÍAZ PAZOS, P. T. (2003): Astrofísica $\Omega$ Cosmología. http://www.astrocosmo.cl/index.htm/

DURKHEIM, E. (1914): La Conception sociale de la religion. En Le Sentiment religieux à l' heure actuelle. Troisième Entretien. La Conception sociale de la religion, Union de Libres Penseurs et de Libres Croyants pour la Culture Morale. Paris: Vrin, 97-105, págs. 142-3.

ELIADE, M. (1951): Le mythe de l'eternel retour. Archétypes et répetitions, Paris , Gallimard. Trad. en Madrid, Alianza.

EVOLUTION WEB SITES. (2002): http://www.people.virginia.edu/ rjh9u/evolution.html 
FABRIS, R. (1983): Gesù di Nazareth. Storia e interpretazione. Assissi, Citadella Editrice. Trad. en Salamanca, Ed. Sígueme, 1985, 343 pp.

FAITH AND REASON (2002): http://www.counterbalance.net/introvid/index-frame.html

FAUL, H. \& FAUL, C. (1983): It Began with a Stone. A History of Geology from the Stone Age to the Age of Plate Tectonics. John Wiley \& Sons.

FINKELSTEIN, I. \& SILBERMAN, N. A. (2001): The Bible Unearthed. Archeology's new vision of Ancient Israel and the Origin of its Sacred Texts. New York, Touchstone.

FORTEY, R. (2000): El Mar Negro, ¿hijo del Diluvio? Mundo Científico-La Recherche, RBA Revistas, Barcelona, 210, págs. 56-59.

FRIEDMAN, R. E. (1987): Who Wrote the Bible. New York, Summit/Simon and Schuster. Trad. en Martínez Roca.

FROEDE, C. R. \& REED, J. K. (1999): Assessing Creationist Stratigraphy with Evidence from the Gulf of Mexico. Creation Research Society Quarterly, Vol. 36, No. 2, September.

GILLESPIE, C. C. (1959): Genesis and Geology: A Study in the Relations of Scientific Thought, Natural Theology, and Social Opinion in Great Britain, 1790-1850. New Cork, Harper Torchbooks.

GONZÁLEZ-BLANCO, E. (1934): Introducción. Evangelios Apócrifos. Librería Bergua, Madrid, 3 vols.

GORDON, R., HOFMANN, A. \& RUCK, C. A. P. (1978): The Road to Eleusis. Unveiling the Secret of the Mysteries. NY, Harcourt Brace. Trad. en Madrid, Fondo de Cultura Económica, 1978, El camino a Eleusis. Una solución al enigma de los misterios, 235 pp.

GOULD, S. J. (1987): Time's Arrow Time's Cycle: Myth and Metaphor in the Discovery of Geological Time. Cambridge (Mass.) \& London, Harvard University Press.

GREENBERG, G. (2000): 101 Myths of the Bible. How Ancient Scribes Invented Biblical History. Naperville, Sourcebooks, Inc. Traduc. en Argentina, Océano.

GRUNBERGER, R. (1971): A Social History of the Third Reich. London, Widenfel \& Nicholson. Trad. en Barcelona, Destino, 1974, 563 pp.

GUYAU, J. M. (1887): L'irreligion de l'avenir. Paris, Alcan, 479 pp.

HABER, F. C. (1959): The Age of the World: Moses to Darwin. Baltimore, Johns Hopkins University Press.

HALE, J. R., ZEILINGA, J., CHANTON, J.P. \& SPILLER, H.A. (2003): El oráculo de Delfos. Barcelona, Investigación y Ciencia, 325, 44-51.

HALPERN, B. (1981): The Constitution of the Monarchy in Israel. Harvard Semitich Monographs, Decatur, Ga., Scholars Press.

HARRIS, G. M. and BEARDOW, A. P. (1995): The destruction of Sodom and Gomorrah: a geotechnical perspective. Quarterly Journal of Engineering Geology, 28 (4), págs. 349-362.

HEIDEL, A. (1951): The Babilonian Genesis, University of Chicago Press, 2th edition.

HEMPEL, C. G. (1966): Philosophy of Natural Science. N.J., Prentice Hall. Trad. en Madrid, Alianza, Filosofía de la Ciencia Natural, 1973, 168 pp.

HENNING, R. (1950): Wo lag das Paradies? Berlin, Verlag des Druckhauses Templehof. Trad. en Barcelona, Bruguera, Grandes enigmas del Universo, 538 pp.

HERENCIA CRISTIANA (2003): http://www.herenciacristiana.com/

IBARRETA, R.H. de (1915): La religión al alcance de todos. Reimpresión en 1987 en Barcelona, Daniel's Libros, $381 \mathrm{pp}$.

ISAAK, M. (1998): Problems with a Global Flood. http://www.talkorigins.org/faqs/faq-noahs-ark.html

JACKSON, M. (2003): A Christian response to Darwinism theories of Evolution. http:// www.bbc.co.uk/education/darwin/leghist/jackson.htm

JONES, O. (2003): Un retrato del inquilino de la Casa Blanca. Madrid, El Mundo, 6 de septiembre, págs. 26-27.

JUAN PABLO II. (1980): Carta apostólica con ocasión del XVI Centenario de la muerte de San Basilio.

KAUTSKY, K. (1908): Orígenes del Cristianismo. Edic. castellana en Quimantú, Santiago, Chile, 1973.

KELLER, W. (1954): La Biblia tenía razón. Reimpresión en 2000 en Barcelona, Círculo de Lectores.

LÉVI-STRAUSS, C. (1966): The Savage Mind. Chicago University Press, trad. en Fondo de Cultura Económica. 
LEWIS C.L.E. \& KNELL S.J. (eds.) (2001): The Age of the Earth: From 4004 BC to AD 2002. London, The Geological Society.

MARTÍNEZ DÍEZ, G. (2001): El Cid histórico. Barcelona, Planeta, 472 pp.

MIGUEL A. de. La España de nuestros abuelos. 1998. Madrid, Espasa, 329 pp.

MORDILlAT, G. et PRIEUR, J. (1999): Jésus contre Jésus. Paris, Editions du Seuil. Trad. en Ed. Algar, Alzira, $378 \mathrm{pp}$.

NATIONAL ACADEMY OF SCIENCES (1999): Science and Creationism: A View from the National Academy of Sciences, $2^{\text {nd }}$ edition, USA. http://www.nap.edu/html/creationism/

NUMBERS R. L. (1992): The Creationists: The Evolution of Scientific Creationism. New Cork, Alfred A Knopf.

PELAYO, F. (1996): Del Diluvio al megaterio. Los orígenes de la Paleontología en España. Madrid, CSIC, Cuadernos Galileo de Historia de la Ciencia, 16, 310 pp.

PLIMER I. R. (1994): Telling Lies for God: Reason vs. Creationism. Sydney, Random House.

RAVENSCROTF, T. (1991): The Spear of Destiny. Trad. en Barcelona, Robinbook, El pacto satánico, $370 \mathrm{pp}$.

RENAN, E. (1863): Vie de Jésus. Paris, Michel Lévy Frères, edic. de 1907. Trad. castellana en Edaf.

RYAN, W. \& PITMAN, W. (1998): Noah's Flood: The New Scientific Discoveries about the Event that changed History. New York, Simon \& Schuster. Hay trad. en castellano, 319 pp.

SÁNCHEZ CARO, J. M. (1998): Para una historia de la Biblia en España. Varia notitia. Estudios Bíblicos 57, págs. 644-657.

Santa Biblia. Traducida de la «Vulgata» latina a la luz de los originales hebreo y griego por el P. José Manuel Petisco, S. J. Valencia, Editorial Alfredo Ortells, 1998, 1225 pp.

SARFATI, J. (1998): Problems with a Global Flood? http://www.trueorigin.org/arkdefen.asp

SCHOENFIELD, H. J. (1965): The Passover Plot. London, Elements Book Ltd. Trad. en Martínez Roca, El complot de Pascua, 1987, 239 pp.

SCIENCE NEWS (1977): Ararat Ark Wood Dated at 700 A.D. March, 198-199.

SEQUEIROS, L. (2002): Historia de la Paleontología española. Boletín de la Comisión de Historia de la Geología en España. Granada, Soc. Geol. de España, 18, 9-12.

SEQUEIROS, L. (2000): El Geocosmos de Athanasius Kircher: un encuentro con la Filosofía y la Teología desde las Ciencias de la Naturaleza en el siglo XVII. Facultad de Teología de Granada. $115 \mathrm{pp}$.

SHANKS, H. (1998): Los manuscritos del Mar Muerto. Paidós, 398 pp.

TEILHARD DE CHARDIN, P. (1955-1976): Euvres. Paris, Editions du Seuil, 13 vols.

THE EVOLUTION EDUCATION SITE RING (2002): Creation Science and Earth History http:// www.geocities.com/earthhistory/

TOKAREV, S. A. (1979): Historia de las religiones. Madrid, Akal, 530 pp.

TOULMIN, S. E. \& GOODFIELD, J. (1982): The Discovery of Time. University of Chicago Press. VIDAL, C. (1995): Historias curiosas del ocultismo. Madrid, Espasa-Calpe, 227 pp.

VITALIANO, D. (1973): Legends of the Earth: their Geologic Origins. Bloomington, Indiana University Press. Trad. en Salvat, Barcelona, Leyendas de la Tierra, $280 \mathrm{pp}$.

VOLTAIRE (1764): Dictionnaire Philosophique. Trad. Castellana en Barcelona, Edaf.

VIRGILI, C. (2003): Lyell. El fin de los mitos geológicos. Madrid, Nívola, 318 pp.

WITHCOMB, J.C. \& Morris, H.M. (1989): The Genesis Flood: the Biblical Record and its Scientific Implications. Presby \& Reformed Publish. Co., 518 pp.

WOOD, B.G. (1999): The Discovery of the Sin Cities of Sodom and Gomorrah. Bible and Spade, summer, 67-80.

ZICYNSKI, J. (1998): Diálogo entre ciencia y fe ante las cuestiones filosóficas de la física actual. Grupo de investigación sobre Ciencia, Razón y Fe, Universidad de Navarra. http://www.unav.es/ cryf/dialogoentrecienciayfe.html 